\title{
Optogenetic activation of parvalbumin and somatostatin interneurons selectively restores theta-nested gamma oscillations and oscillation-induced spike timing- dependent long-term potentiation impaired by amyloid $\beta$ oligomers
}

Kyerl Park ${ }^{1 \dagger}$, Jaedong Lee ${ }^{1 \dagger}$, Hyun Jae Jang ${ }^{1}$, Blake A. Richards ${ }^{2}$, Michael M. Kohl ${ }^{3}$ and Jeehyun Kwag ${ }^{1 *}$ (D)

\begin{abstract}
Background: Abnormal accumulation of amyloid $\beta_{1-42}$ oligomers $\left(A \mathrm{O}_{1-42}\right)$, a hallmark of Alzheimer's disease, impairs hippocampal theta-nested gamma oscillations and long-term potentiation (LTP) that are believed to underlie learning and memory. Parvalbumin-positive (PV) and somatostatin-positive (SST) interneurons are critically involved in theta-nested gamma oscillogenesis and LTP induction. However, how $A \mathrm{BO}_{1-42}$ affects PV and SST interneuron circuits is unclear. Through optogenetic manipulation of PV and SST interneurons and computational modeling of the hippocampal neural circuits, we dissected the contributions of PV and SST interneuron circuit dysfunctions on $\mathrm{A} \mathrm{O}_{1-42}$-induced impairments of hippocampal theta-nested gamma oscillations and oscillation-induced LTP.

Results: Targeted whole-cell patch-clamp recordings and optogenetic manipulations of PV and SST interneurons during in vivo-like, optogenetically induced theta-nested gamma oscillations in vitro revealed that $\mathrm{A} \mathrm{O}_{1-42}$ causes synapse-specific dysfunction in PV and SST interneurons. $A \mathrm{BO}_{1-42}$ selectively disrupted CA1 pyramidal cells (PC)-to-PV interneuron and PV-to-PC synapses to impair theta-nested gamma oscillogenesis. In contrast, while having no effect on PC-to-SST or SST-to-PC synapses, $\mathrm{A} \mathrm{O}_{1-42}$ selectively disrupted SST interneuron-mediated disinhibition to CA1 PC to impair theta-nested gamma oscillation-induced spike timing-dependent LTP (tLTP). Such $A \beta \mathrm{O}_{1-42}$-induced impairments of gamma oscillogenesis and oscillation-induced tLTP were fully restored by optogenetic activation of PV and SST interneurons, respectively, further supporting synapse-specific dysfunctions in PV and SST interneurons. Finally, computational modeling of hippocampal neural circuits including CA1 PC, PV, and SST interneurons confirmed the experimental observations and further revealed distinct functional roles of PV and SST interneurons in theta-nested gamma oscillations and tLTP induction.
\end{abstract}

Conclusions: Our results reveal that $\mathrm{A} \mathrm{O}_{1-42}$ causes synapse-specific dysfunctions in PV and SST interneurons and that optogenetic modulations of these interneurons present potential therapeutic targets for restoring hippocampal network oscillations and synaptic plasticity impairments in Alzheimer's disease.

(Continued on next page)

\footnotetext{
* Correspondence: jkwag@korea.ac.kr

${ }^{\dagger}$ Kyerl Park and Jaedong Lee contributed equally to this work.

'Department of Brain and Cognitive Engineering, Korea University, Seoul

02841, Republic of Korea

Full list of author information is available at the end of the article
}

(c) The Author(s). 2020 Open Access This article is distributed under the terms of the Creative Commons Attribution 4.0 International License (http://creativecommons.org/licenses/by/4.0/), which permits unrestricted use, distribution, and reproduction in any medium, provided you give appropriate credit to the original author(s) and the source, provide a link to the Creative Commons license, and indicate if changes were made. The Creative Commons Public Domain Dedication waiver (http://creativecommons.org/publicdomain/zero/1.0/) applies to the data made available in this article, unless otherwise stated. 
(Continued from previous page)

Keywords: Alzheimer's disease, Amyloid beta oligomers, Hippocampus, Optogenetics, Parvalbumin interneuron, Somatostatin interneuron, Theta-nested gamma oscillations, Spike timing-dependent long-term potentiation, Synapsespecific dysfunction

\section{Background}

Alzheimer's disease is a neurodegenerative disease characterized by a progressive decline in cognitive and mnemonic functions [1, 2]. Abnormal accumulation of amyloid $\beta_{1-42}$ oligomers $\left(\mathrm{A} \beta \mathrm{O}_{1-42}\right)$ is a hallmark of Alzheimer's disease [1-4] and $\mathrm{A} \mathrm{O}_{1-42}$-induced impairments of gamma oscillations [5-10] and long-term synaptic plasticity $[3,4,11,12]$ are believed to contribute to the memory deficits observed in Alzheimer's disease. In particular, hippocampal theta-nested gamma oscillations observed during spatial memory processing [13-15] have been shown to support the induction of long-term potentiation (LTP) [16-19]. Thus, $\mathrm{A} \beta \mathrm{O}_{1-42}$ may impair memory by disrupting GABAergic inhibitory circuits, which underlie oscillogenesis [14, 20-25]. Indeed, there is now increasing experimental evidence showing that $\mathrm{A} \mathrm{O}_{1-42}$ reduces GABA synaptic transmission [26-28], causes excitation/inhibition imbalances $[9,12,27,28]$, and even diminishes the number of GABAergic synapses/ terminals onto pyramidal cells [29]. Also, parvalbuminpositive (PV) and somatostatin-positive (SST) interneurons, the two major subtypes of hippocampal interneurons [30] that are critically involved in oscillogenesis $[24,25,31]$, are reported to be impaired in mouse models of Alzheimer's disease [5-8, 27, 32, 33]. PV interneurons' spike amplitude, membrane potential, and firing rate are decreased $[5,7]$ while SST interneurons' structural plasticity and axonal sprouting are impaired in Alzheimer's disease mouse models [27, 32]. Surprisingly, the neural circuit mechanism by which dysfunction of PV and SST interneurons contributes to $A \mathrm{O}_{1-42}$-induced impairment of oscillogenesis and LTP is unclear. If uncovered, it could help researchers find novel therapeutic targets for Alzheimer's disease. Recently, optogenetic stimulation of channelrhodopsin-2 (ChR2)-expressing hippocampal CA1 pyramidal cells (PCs) at theta-frequency was shown to induce in vivo-like theta-nested gamma oscillations in the CA1 area of acute hippocampal slices in vitro [34]. This provides a novel model in which to perform targeted whole-cell patch-clamp recordings and selective optogenetic modulation of PV or SST interneuron activity during optogenetically induced theta-nested gamma oscillations and LTP induction. We have used this approach to investigate neural circuit dysfunction in hippocampal slices treated with $\mathrm{A} \beta \mathrm{O}_{1-42}$. We found that $\mathrm{A} \beta \mathrm{O}_{1-42}$ caused selective dysfunctions in reciprocal synapses between PC and PV interneurons, which impaired gamma oscillations and desynchronized the spike phases of PC and PV interneurons relative to gamma oscillations. While $\mathrm{A} \mathrm{BO}_{1-42}$ had no effect on PC-to-SST or SST-to-PC synapses, it specifically disrupted SST interneuron-mediated disinhibition to $\mathrm{PC}$ resulting in the impairment of theta-nested gamma oscillation-induced spike timing-dependent LTP (tLTP). Selective optogenetic activation of PV interneurons restored gamma oscillations while selective optogenetic activation of SST interneurons restored theta-nested gamma oscillation-induced tLTP. These results demonstrate that $\mathrm{A} \mathrm{O}_{1-42}$-induced synapse-specific dysfunctions in PV and SST interneurons may explain the concomitant impairments of hippocampal gamma oscillations and synaptic plasticity in Alzheimer's disease. Moreover, using a computational network model of PC, $\mathrm{PV}$, and SST interneurons, we further demonstrate that PV and SST interneurons targeting different compartments of the CA1 PC have distinct functional roles in oscillogenesis and tLTP induction.

\section{Results}

$A \mathrm{O}_{1-42}$ impairs in vivo-like, optogenetically induced theta-nested gamma oscillations in hippocampal slices

To create an in vitro model of $\mathrm{A} \mathrm{O}_{1-42}$-induced pathology in hippocampal slices, we prepared $A \beta \mathrm{O}_{1-42}$ by oligomerizing $A \beta_{1-42}$ following a previously described protocol [4] (see the "Methods" section). Generation of $\mathrm{A} \mathrm{BO}_{1-42}$ was confirmed by Western blot analysis of SDS-PAGE (Fig. 1a) and native PAGE (Additional file 1: Figure S1). To induce blue light-induced theta-nested gamma oscillations, we injected adeno-associated virus (AAV) carrying ChR2 (AAV-CaMKII-ChR2-mCherry) into the CA1 area of the hippocampus (Fig. 1b), which led to the expression of ChR2 in CA1 PCs in hippocampal slices in vitro (Fig. 1c). We optically stimulated ChR2-expressing PCs using $5 \mathrm{~Hz}$ sinusoidal blue light (470 nm, Fig. 1d) in dimethyl sulfoxide (DMSO)-treated hippocampal slices which reliably reproduced thetanested gamma oscillations as observed in the band-pass filtered local field potential (LFP) (Fig. 1e, black traces, top) and in the spectrogram [34] (Fig. 1e, bottom) that persisted for over $40 \mathrm{~min}$ (Additional file 2: Figure S2). However, 20-min treatment of $\mathrm{A} \mathrm{O}_{1-42}(200 \mathrm{nM})$ in the same slice significantly decreased the power of gamma oscillations in the LFP (Fig. 1f, red traces, top) and in the spectrogram (Fig. 1f, bottom), while 20-min 


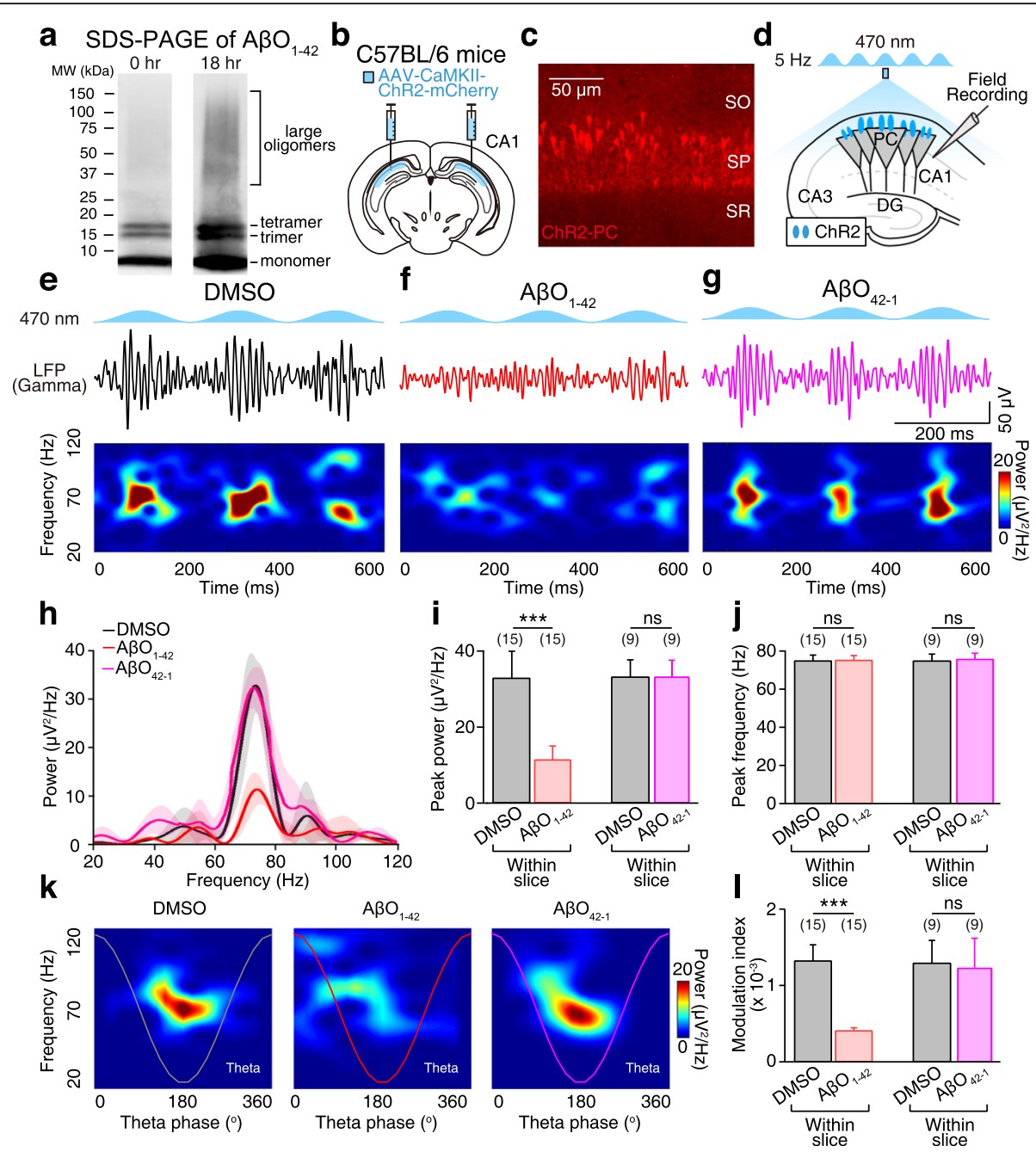

Fig. $1 \mathrm{ABO}_{1-42}$ impairs in vivo-like, optogenetically induced theta-nested gamma oscillations in hippocampal slices. a Western blot of SDS-PAGE showing $\mathrm{ABO}_{1-42}$ (trimer, tetramer, and large oligomers) after incubation at $4^{\circ} \mathrm{C}$ for $0 \mathrm{~h}$ (left) and $18 \mathrm{~h}$ (right). b Micro-injection of AAV-CaMKIIChR2-mCherry into hippocampal CA1 area of C57BL/6 mice. c Fluorescence image of ChR2-expressing PCs (ChR2-PC). SO, stratum oriens; SP, stratum pyramidale; SR, stratum radiatum. d Experimental schematic showing sinusoidal (5 Hz) blue light (470 nm) stimulation of ChR2-PC and field recordings in the CA1 area of hippocampal slices in vitro. e-g Sinusoidal blue light stimulation induces theta-nested gamma oscillations as shown in the band-pass filtered LFP (top) and the corresponding spectrograms (bottom) in DMSO-treated slice (e), after 20-min treatment of either $\mathrm{ABO}_{1-42}(\mathbf{f})$, or $\mathrm{ABO}_{42-1}(\mathbf{g})$. $\mathbf{h}-\mathbf{j}$ Mean power spectral density (PSD, shade indicates SEM) of gamma oscillations (h), mean peak power (i), and mean peak frequency (j) of gamma oscillations in DMSO-treated slice (black) and following 20 min of ${\mathrm{A} \beta \mathrm{O}_{1-42}}_{2}$ treatment in the same slices (red) or in DMSO-treated slice (black) and following 20 min $\mathrm{ABO}_{42-1}$ treatment in the same slices (magenta). $\mathbf{k}$, I Representative comodulograms showing phase-amplitude coupling of gamma oscillations to theta cycle $(\mathbf{k})$ and mean modulation index (I) in each condition. Paired Student's $t$ test $\left(\mathbf{i}, \mathbf{j}, \mathbf{I},{ }^{* * *} p<0.001\right.$, ns: not significant). Data are represented as mean \pm SEM

treatment of $\mathrm{A}_{\mathrm{O}_{42-1}}$, an inactive peptide control for $\mathrm{A} \beta \mathrm{O}_{1-42}$, in the same slice of DMSO-treated slices had no effect (Fig. 1g, magenta). Power spectral density (PSD) analysis of theta-nested gamma oscillations (Fig. 1h) revealed that peak power of gamma oscillations in the DMSO-treated slice (Fig. 1i, black) was impaired by $\mathrm{A} \mathrm{OO}_{1-42}$ (Fig. 1i, red), but not by $\mathrm{A} \mathrm{O}_{42-1}$ (Fig. 1i, magenta), while peak frequency was spared in all conditions (Fig. 1j). Moreover, phase-amplitude coupling analysis of gamma oscillations to the trough of theta cycle (Fig. 1k) revealed that the coupling strength, quantified by the modulation index (see the "Methods" section), was significantly decreased by $\mathrm{A} \beta \mathrm{O}_{1-42}$, but not by $\mathrm{A} \beta \mathrm{O}_{42-1}$, compared to that in the DMSO-treated slices (Fig. 11). We replicated these effects in different slices treated with $\mathrm{A} \beta \mathrm{O}_{1-42}$ for 20 min before performing field recording (Additional file 3: Figure S3); thus, the reduction in oscillatory activity was not caused by recording duration. These results show that $\mathrm{A} \mathrm{O}_{1-42}$-treated slices with optical stimulation of ChR2-expressing CA1 PCs can replicate gamma oscillations impairment as observed in Alzheimer's disease mouse models in vivo [5-8]. 


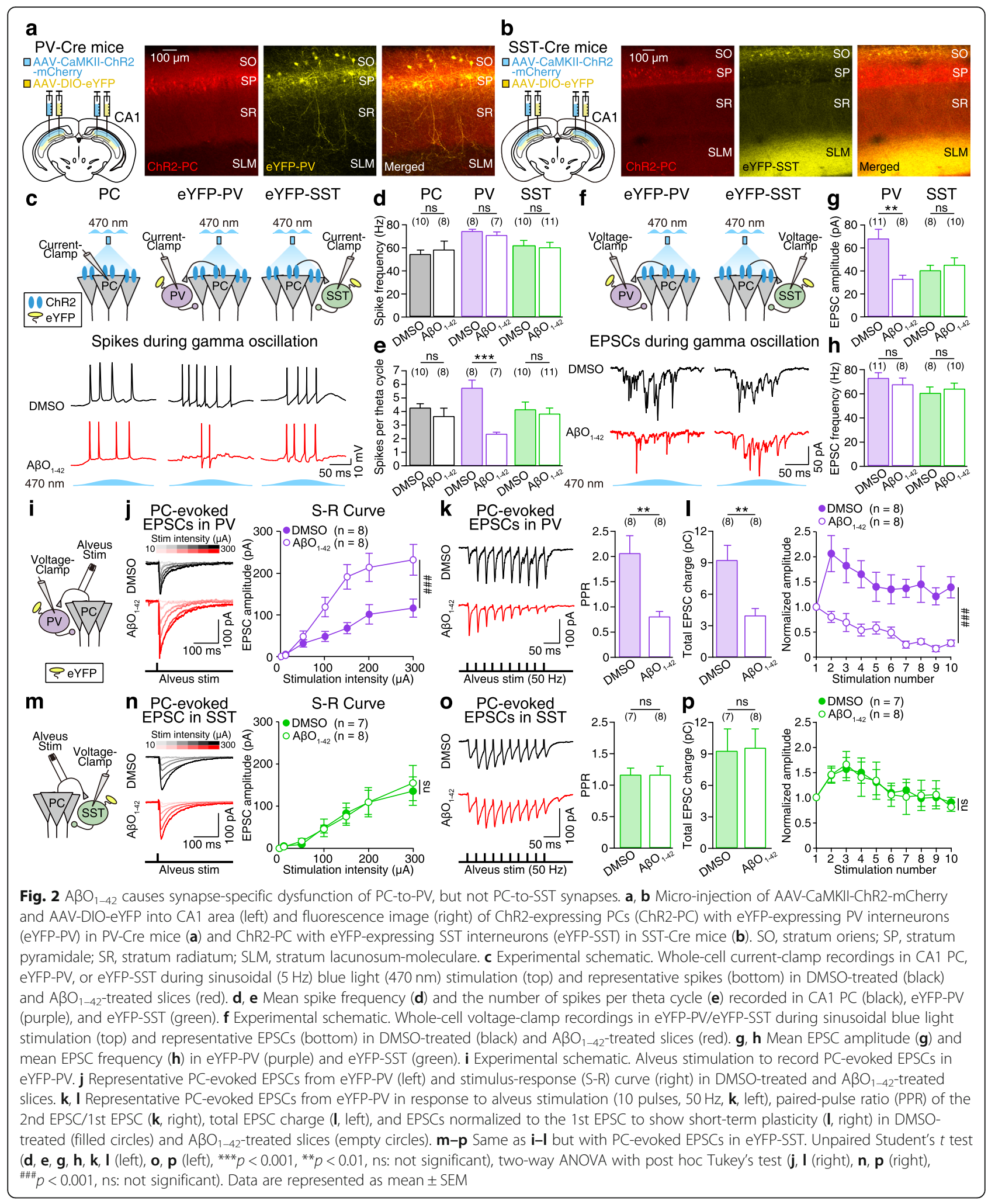

$A \mathrm{O}_{1-42}$ causes synapse-specific dysfunction of PC-to-PV, but not PC-to-SST synapses

To determine whether alterations to either PV or SST interneurons contributed to the reduction in peak power of

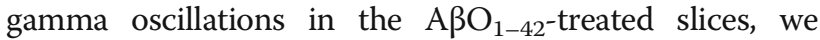
expressed ChR2 in CA1 PCs and enhanced yellow fluorescent protein (eYFP) in either PV or SST interneurons in PV-Cre (Fig. 2a) or SST-Cre mice (Fig. 2b), respectively. 
We then performed current-clamp recordings to record spikes in CA1 PCs, eYFP-expressing PV, and SST interneurons during blue light-induced theta-nested gamma oscillations (Fig. 2c). We found that all neuronal types spiked at gamma-frequency in DMSO-treated slices (Fig. 2c, black traces, Fig. 2d). $\mathrm{A} \mathrm{O}_{1-42}$ had no effect on neither spike frequencies (Fig. 2c, red traces, Fig. 2d), nor the intrinsic membrane properties (Additional file 4: Figure S4) of PV and SST interneurons, which could explain why the peak frequency of gamma oscillations was intact even after $\mathrm{A} \beta \mathrm{O}_{1-42}$ treatment (Fig. 1j). However, the number of spikes per theta cycle was reduced only in PV interneurons (Fig. 2e).

Since the spiking of hippocampal CA1 interneurons is in large part driven by CA1 PC's excitatory inputs to the interneurons [35], we investigated whether the treatment of $\mathrm{A} \mathrm{O}_{1-42}$ affected CA1 PC's excitatory inputs to PV and SST interneurons. We performed voltage-clamp recordings in eYFP-expressing PV or SST interneurons during blue light-induced theta-nested gamma oscillations in DMSO-treated and $\mathrm{A} \mathrm{O}_{1-42}$-treated slices (Fig. 2f). We found that the amplitude of CA1 PC's excitatory postsynaptic current (EPSC) to PV, but not SST interneuron, was significantly decreased in $A \beta \mathrm{O}_{1-42^{-}}$ treated slices (Fig. 2f, g), while EPSC frequency was unaffected (Fig. 2h). To characterize the $\mathrm{A} \beta \mathrm{O}_{1-42}$-induced synaptic dysfunctions at $\mathrm{CA} 1 \mathrm{PC}-$ to-PV synapse and CA1 PC-to-SST synapse, we first investigated how $\mathrm{A} \mathrm{OO}_{1-42}$ affected the stimulus-response (S-R) curve of these synapses by electrically stimulating the axons of CA1 PC in the alveus of CA1 at different intensities (10, $50,100,150,200$, and $300 \mu \mathrm{A}$ ) and recording the corresponding PC-evoked EPSCs in eYFP-expressing PV interneuron (Fig. 2i, j) or in eYFP-expressing SST interneuron (Fig. $2 \mathrm{~m}, \mathrm{n}$ ). Analysis of the S-R curve revealed that, for each stimulation intensity, $\mathrm{A} \mathrm{O}_{1-42}$ significantly increased the amplitudes of PC-evoked EPSCs in PV (Fig. 2j, right), but not those in SST interneurons (Fig. 2n, right). These results indicate that $\mathrm{A} \mathrm{O}_{1-42}$ increases the initial neurotransmitter release probability of PC-to-PV synapse. To investigate the synaptic locus of EPSC changes, we stimulated the CA1 PC axons using a halfmaximal stimulus (based on the S-R curve in Fig. $2 \mathrm{j}$, $\mathrm{n}$, right; $115-210 \mu \mathrm{A}$ ) and an inter-stimulus interval of 20 $\mathrm{ms}(50 \mathrm{~Hz}, 10$ stimulus) for the analysis of paired-pulse ratio (PPR), total charge, and short-term plasticity of PC-evoked EPSCs in PV (Fig. 2k, l) and SST interneurons (Fig. 2o, p). Paired-pulse facilitation of PC-evoked EPSCs in PV interneurons, as observed in DMSOtreated slices, was converted to paired-pulse depression in $\mathrm{A} \mathrm{O}_{1-42}$-treated slices (Fig. 2k, right). The total charge of PC-evoked EPSCs in PV (Fig. 2l, left), analyzed by the area of the PC-evoked EPSCs in Fig. 2k (left), was significantly decreased by $\mathrm{A} \beta \mathrm{O}_{1-42}$. Furthermore, short- term facilitation of PC-evoked EPSCs in PV interneurons, as observed in DMSO-treated slices, was converted to short-term depression in $\mathrm{A} \mathrm{O}_{1-42}$-treated slices (Fig. 2l, right). These results indicate that $\mathrm{A} \beta \mathrm{O}_{1-42}$ causes presynaptic depression at PC-to-PV synapse, which led to a decrease in CA1 PC-evoked excitatory synaptic inputs onto PV interneurons. Thus, $\mathrm{A} \beta \mathrm{O}_{1-42^{-}}$ induced gamma oscillation impairment may be due to dysfunction of presynaptic mechanisms at PC-to-PV synapses. In contrast, $\mathrm{A} \mathrm{O}_{1-42}$ had no effect on PPR, total charge, or short-term plasticity of CA1 PC-evoked EPSCs in SST interneurons (Fig. 2o, p). Therefore, $\mathrm{A} \beta \mathrm{O}_{1-42}$ causes presynaptic dysfunctions at CA1 PC-tointerneuron synapses which is target-specific.

\section{$A \mathrm{BO}_{1-42}$ causes synapse-specific dysfunction of PV-to-PC synapses, but not SST-to-PC synapses}

Blue light-induced theta-nested gamma oscillations are most likely generated by reciprocal synapses between PCs and interneurons [34], according to the pyramidalinterneuron network gamma (PING) model [14, 21, 23]. In accordance with this model, voltage-clamp recordings in CA1 PCs during blue light-induced gamma oscillations (Fig. 3a, top) revealed that inhibitory postsynaptic currents (IPSCs) occurred at gamma-frequencies in DMSO-treated slices (Fig. 3a, bottom, black trace, Fig. 3f), which were $\mathrm{GABA}_{\mathrm{A}}$ receptor-mediated as they were completely blocked by GABAzine (SR95531, $5 \mu \mathrm{M}$, Fig. 3a, bottom, gray trace; Fig. 3f, g). $\mathrm{A} \mathrm{O}_{1-42}$ significantly decreased the amplitude of these IPSCs (Fig. 3a, bottom, red trace; Fig. 3g), potentially accounting for the observed reduction in peak power of gamma in $\mathrm{A} \mathrm{O}_{1-}$ 42 -treated slices (Fig. 1h, i). To determine which interneuron subtype was responsible for the reduction of IPSC in PC in $\mathrm{A} \mathrm{O}_{1-42}$-treated slices, we optogenetically inactivated either PV or SST interneuron during gamma oscillations by co-injecting two different AAV viruses to CA1, one carrying ChR2 and the other carrying enhanced Arch (AAV-DIO-Arch-eYFP) in order to express ChR2 in PCs and Arch in either PV (Fig. 3b) or SST interneurons (Fig. 3c). During theta-nested gamma oscillations in DMSO-treated slices, inactivation of Archexpressing PV interneurons (Fig. 3d) and Archexpressing SST interneurons (Fig. 3e) by yellow light $(590 \mathrm{~nm})$ had no effect on IPSC frequency in CA1 PCs (Fig. 3f). However, IPSC amplitude in CA1 PC was significantly reduced only by inactivation of Archexpressing PV interneurons in the DMSO-treated slices (Fig. 3g), which was similar to that recorded in $\mathrm{A} \mathrm{O}_{1-42^{-}}$ treated slices (Fig. 3a, red trace, Fig. 3g). Inactivation of Arch-expressing PV interneurons in $\mathrm{A} \mathrm{O}_{1-42}$-treated and DMSO-treated slices had the same effect in reducing IPSC amplitudes (Fig. 3d, red trace, Fig. 3g) while inactivation of Arch-expressing SST interneurons in 


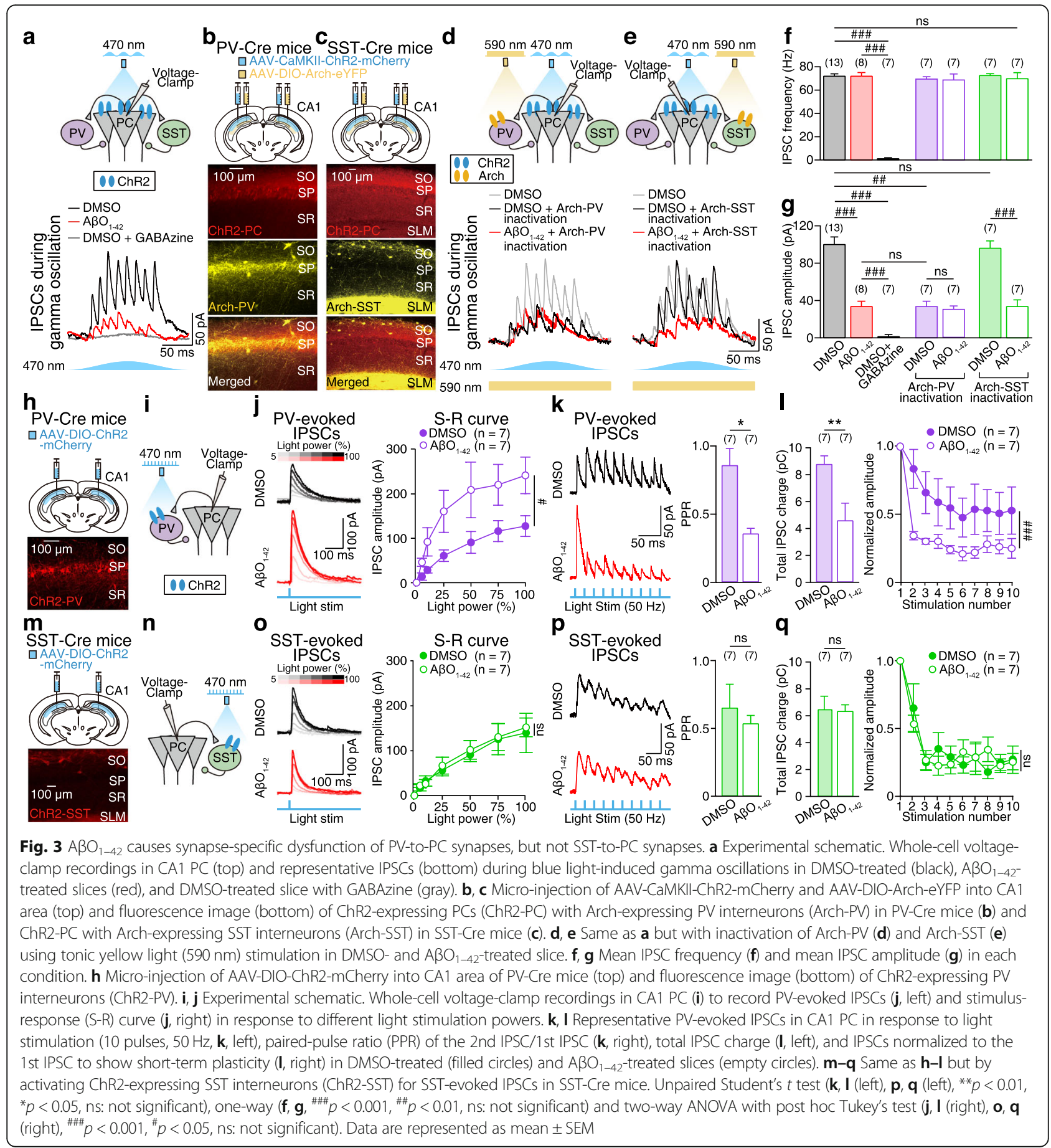

$\mathrm{A} \mathrm{OO}_{1-42}$-treated slices significantly reduced the IPSC amplitude compared to that in the DMSO-treated slices (Fig. 3e, red traces, Fig. 3g). Moreover, the peak power of gamma oscillations was also decreased only by inactivation of Arch-expressing PV interneuron (Additional file 5: Figure S5) while inactivation of Archexpressing SST interneuron had no effect on gamma oscillations (Additional file 6: Figure S6), indicating $\mathrm{A} \beta \mathrm{O}_{1-42}$-induced reduction of IPSC in CA1 PCs as well as the reduction of peak power of gamma oscillations may be due to dysfunction of PV interneurons. To rule out the possibility of yellow light having any direct effects on the reduction of gamma oscillation power via activation of ChR2 in CA1 PCs, we recorded synaptic currents in ChR2-expressing PCs and LFPs in the nearby tissue during sinusoidal $(5 \mathrm{~Hz})$ blue $(470 \mathrm{~nm})$, green $(565 \mathrm{~nm})$, and yellow light $(590 \mathrm{~nm})$ stimulation (Additional file 7: Figure S7a-c). We found that green light 
induced synaptic currents and gamma oscillations in the LFP while yellow light stimulation had no effect on either of them (Additional file 7: Figure S7d, e). In order to characterize the $\mathrm{A} \beta \mathrm{O}_{1-42}$-induced synaptic dysfunctions at PV-to-CA1 PC synapse and SST-to-CA1 PC synapse, we expressed ChR2 in PV (Fig. 3h) and SST interneurons (Fig. 3m) and analyzed the S-R curve of these synapses by optically stimulating ChR2-expressing PV interneurons (Fig. 3i) and ChR2-expressing SST interneurons (Fig. 3n) at different light powers $(5,10,25,50,75,100 \%$ of maximal light power $(15 \mathrm{~mW}))$ and recorded the corresponding PV-evoked IPSCs in PC (Fig. 3j) and SST-evoked IPSCs in PC (Fig. 3o). Analysis of the S-R curve revealed that, for each stimulation intensity, $\mathrm{A} \beta \mathrm{O}_{1-42}$ significantly increased the amplitudes of PV-evoked IPSCs in PC (Fig. 3j), but not SST-evoked IPSCs in PC (Fig. 3o), suggesting that $A \mathrm{O}_{1-}$ ${ }_{42}$ increases the initial neurotransmitter release probability of PV-to-PC synapse. To investigate the synaptic locus of IPSC changes, we optically stimulated ChR2-expressing PV interneurons and ChR2-expressing SST interneurons using a half-maximal light power (based on S-R curve in Fig. 3j, o; 3.75-9 mW) and an inter-stimulus interval of 20 ms $(50 \mathrm{~Hz}, 10$ stimulus) for the analysis of PPR, total charge, and short-term plasticity of PV-evoked IPSCs (Fig. 3k, l) and SST-evoked IPSCs (Fig. 3p, q). A $\mathrm{BO}_{1-42}$ significantly enhanced the paired-pulse depression in PVevoked IPSCs in PC, as observed in DMSO-treated slice (Fig. 3k, right). The total charge of PV-evoked IPSCs in PC was significantly decreased by $\mathrm{A} \mathrm{O}_{1-42}$ (Fig. 3l, left). Furthermore, short-term depression of PV-evoked IPSCs in $\mathrm{PC}$, as observed in DMSO-treated slice was even more enhanced in $\mathrm{A} \mathrm{O}_{1-42}$-treated slices (Fig. 31, right) while it had no effect on SST-evoked IPSCs (Fig. 3p, q). Together, these results indicate that $A \beta \mathrm{O}_{1-42}$ specifically disrupted reciprocal PC-to-PV and PV-to-PC synapses, which would likely impair gamma oscillations, while $\mathrm{A} \mathrm{O}_{1-42}$ had no effect on PC-to-SST or SST-to-PC synapses.

\section{Optogenetic activation of PV interneurons restores $A \beta_{1-}$

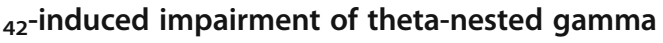 oscillations}

We then asked whether optogenetic activation of PV interneurons could rescue theta-nested gamma oscillations in $\mathrm{A} \mathrm{O}_{1-42}$-treated slices. If so, it would be strong evidence that the dysfunction of PV interneurons was the ultimate cause of reduced theta-nested gamma oscillations in $\mathrm{ABO}_{1-42}$-treated slices. We co-injected AAV viruses carrying ChR2 and C1V1 (AAV-DIO-C1V1-eYFP) (Fig. 4a), an opsin that opens a cation channel with peak excitation centered around green light $(565 \mathrm{~nm})$, in order to express ChR2 in CA1 PC and C1V1 in PV interneurons (Fig. 4b). Since green light activates ChR2expressing PCs (Additional file 7: Figure S7), we optically stimulated C1V1-expressing PV interneurons using yellow light $(590 \mathrm{~nm})$, which activated C1V1-expressing PV interneurons reliably (Additional file 8: Figure S8). Using this preparation, we optically stimulated C1V1expressing PV interneurons with yellow light in $A \beta \mathrm{O}_{1-}$ ${ }_{42}$-treated slices during blue light-induced theta-nested gamma oscillations (Fig. 4c, d). PV interneuron activation successfully restored the peak power of gamma oscillations in $\mathrm{A} \mathrm{O}_{1-42}$-treated slices (Fig. $4 \mathrm{~d}-\mathrm{f}$ ) to the level observed in DMSO-treated slices while maintaining frequency at gamma (Fig. 4g). Phase-amplitude coupling of gamma oscillations to theta cycle in $\mathrm{A} \mathrm{O}_{1-42}$-treated slices was also increased by PV interneuron activation to the level observed in DMSO-treated slices (Fig. 4h, i). Since CA1 PC spike phases relative to gamma oscillations are important for hippocampal spatial information processing [36, 37], we investigated the phase of spikes and postsynaptic currents (PSCs) relative to the gamma cycle. Following the PING model [14, 21, 23], gamma oscillations triggered the activation of CA1 PC spikes, EPSCs in PV interneurons, PV interneuron spikes, then IPSCs in CA1 PCs in sequence (Fig. 4j), with distinct phases relative to ongoing gamma cycles in DMSOtreated slices (Fig. 4k, black bars). The phase-locking of spike/synaptic current was abolished in $\mathrm{A} \mathrm{O}_{1-42}$-treated slices, making it difficult to detect a clear peak in the event phase probability (Fig. 4k, red bars). Nonetheless, optical stimulation of C1V1-expressing PV interneurons in $\mathrm{A} \beta \mathrm{O}_{1-42}$-treated slices restored phase-locking of spikes/synaptic currents (Fig. 4k, yellow bars). The strength of phase-locking, as measured by the length of the resultant vector in the phase vector plot, was indeed restored by optical stimulation of C1V1-expressing PV interneurons (Fig. 4l, $\mathrm{m}$ ). The mean vector phases were also rescued by optical stimulation of C1V1-expressing PV interneurons (Fig. 4n). These data show that optogenetic activation of PV interneurons restores gamma power and resynchronizes spikes/synaptic inputs to gamma cycles. This supports the idea that $\mathrm{A} \mathrm{O}_{1-42}$-induced reductions in theta-nested gamma oscillations power are caused by PV interneuron dysfunction.

\section{Optogenetic activation of SST interneurons restores $\mathrm{A} \mathrm{BO}_{1-42}$-induced impairment of theta-nested gamma oscillation-induced tLTP}

Theta-nested gamma oscillations have been shown to support the induction of LTP at Schaffer collateral (SC) synapses [16-19], but a direct experimental demonstration of how CA1 PCs and PV/SST interneurons partake in LTP induction at CA3-to-CA1 synapses during thetanested gamma oscillations is lacking. To remedy this, we paired presynaptic SC stimulation-evoked excitatory postsynaptic potentials (EPSPs) with postsynaptic spike bursts (4 spikes at $100 \mathrm{~Hz}$ repeated at $5 \mathrm{~Hz}$ ) at a delay $(\Delta t)$ of $+10 \mathrm{~ms}$, thereby mimicking CA3 inputs onto 


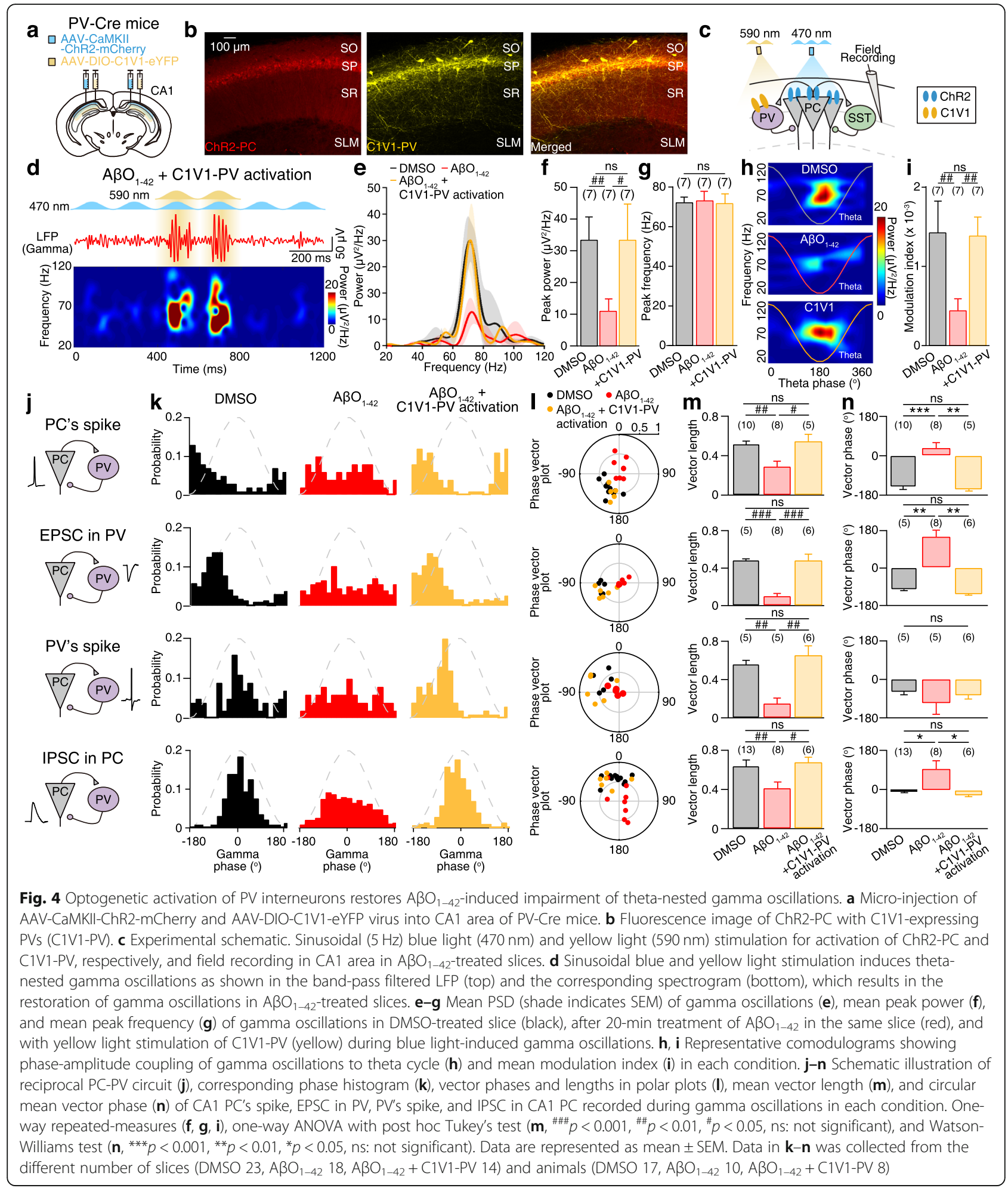

CA1 PCs during theta-nested gamma oscillations (Fig. 5a, b) [38]. We found that this protocol reliably induced robust tLTP at CA3-to-CA1 synapses in DMSO-treated slices (Fig. 5c, f, black filled bar), which was NMDA receptor (NMDAR)-dependent, as it was blocked by
NMDAR antagonist, D-AP5 $(50 \mu \mathrm{M}$, Fig. $5 \mathrm{~d}$, f, black dotted bar). However, NMDAR-dependent tLTP was completely blocked in the $\mathrm{A} \mathrm{O}_{1-42}$-treated slices (Fig. 5e, f, red filled bar). Since PV and SST interneurons' spikes were concurrently activated during theta- 


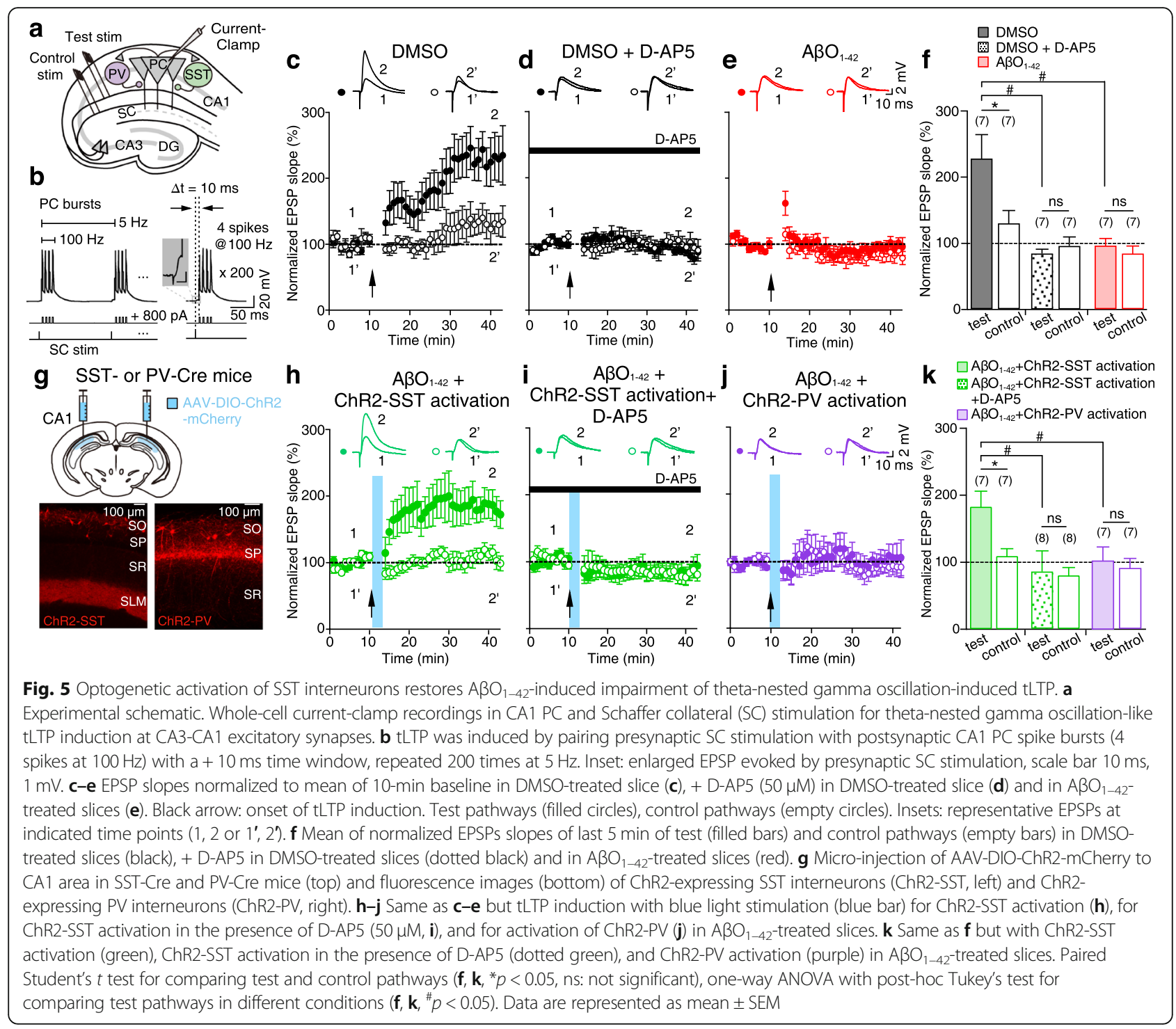

nested gamma oscillations (Fig. 2c) and by alveus stimulation of CA1 PC axons (Additional file 9: Figure S9), $A \beta \mathrm{O}_{1-42}$-induced synaptic dysfunctions of either PV or SST interneurons may have contributed to the observed tLTP impairment. To test this hypothesis, we expressed ChR2 in either SST or PV interneurons in SST-Cre or PV-Cre mice (Fig. 5g) and optically stimulated ChR2-expressing SST or PV interneurons with blue light $(470 \mathrm{~nm})$ during theta-nested gamma oscillation-like tLTP induction in $\mathrm{A}_{3} \mathrm{O}_{1-42}$-treated slices (Fig. $5 \mathrm{~h}-\mathrm{j}$ ). We found that optogenetic activation of SST interneurons in $\mathrm{A} \beta \mathrm{O}_{1-42}$-treated slices could fully restore NMDAR-dependent tLTP (Fig. 5h, k, green filled bar) that was blocked by D-AP5 (Fig. 5i, k, green dotted bar). However, optogenetic activation of PV interneurons in $\mathrm{A} \mathrm{O}_{1-42}$-treated slices could not restore tLTP (Fig. 5j, k, purple filled bar).
$A \mathrm{OO}_{1-42}$ causes selective dysfunction of SST interneuronmediated disinhibition to CA1 PC

How could SST activation have contributed to the restoration of NMDAR-tLTP induction during theta-nested gamma oscillations? SST interneurons, such as oriens lacunosum-moleculare (OLM) cells, inhibit the distal dendrites of PCs in CA1 [39], but they also provide disinhibition of feedforward inhibition activated by SC input to CA1 PC's proximal dendrites [39]. Moreover, optical stimulation of SST interneuron-mediated disinhibition during LTP induction has been shown to enhance LTP [39]. Thus, one possibility is that $A \beta \mathrm{O}_{1-42}$ impairs SST interneuron-mediated disinhibition of proximal dendrites of CA1 PCs, and thereby, tLTP. To investigate this possibility, we recorded SC stimulation-evoked IPSCs from CA1 PCs and compared them with SC stimulation-evoked IPSCs paired with CA1 PC spikes 


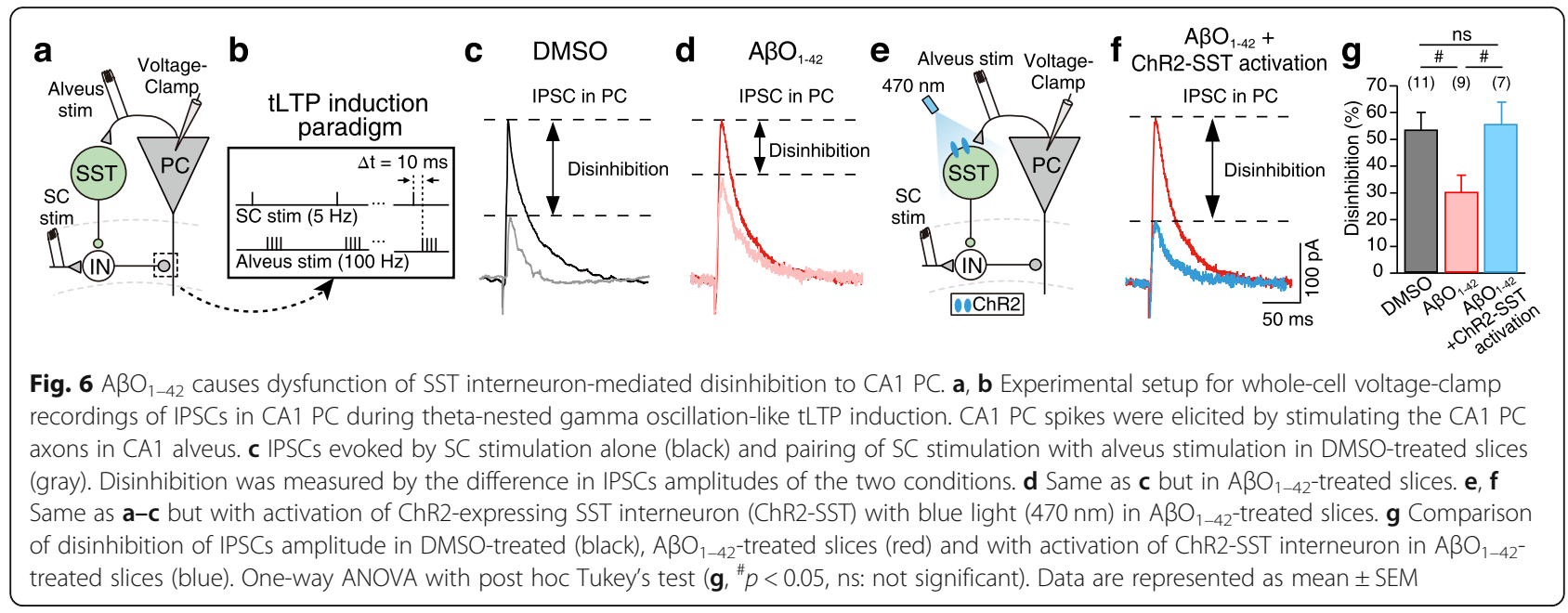

evoked by alveus stimulation (4 spikes at $100 \mathrm{~Hz}$, repeated at $5 \mathrm{~Hz}$ ), which mimics theta-nested gamma oscillationlike tLTP induction, as in Fig. 5b (Fig. 6a, b, Additional file 10: Figure S10). The amplitude of SC stimulation-evoked IPSCs significantly decreased when it was paired with alveus stimulation (Fig. 6c, g, black bar), showing that SST interneurons activated by alveus stimulation resulted in SST interneuron-mediated disinhibition. SST interneuron-mediated disinhibition was significantly decreased in $\mathrm{A} \mathrm{O}_{1-42}$-treated slices (Fig. 6d, g, red bar), but it was fully restored by optical stimulation of ChR2expressing SST interneurons to a level similar to that in DMSO-treated slices (Fig. 6e-g, blue bar). In addition, when SC stimulation was paired with 50-ms-long optical stimulation of ChR2-expressing SST interneurons alone, the amplitude of SC stimulation-evoked IPSCs was similar in both DMSO-treated and $\mathrm{A} \mathrm{O}_{1-42}$-treated slices (Additional file 11: Figure S11), further supporting our hypothesis that optical restoration of SST interneuron-mediated disinhibition underpins the restoration of tLTP induction in $\mathrm{A} \beta \mathrm{O}_{1-42}$-treated slices.

\section{Distinct functional roles of PV and SST interneurons in gamma oscillogenesis and theta-nested gamma oscillation-induced tLTP}

Our data supports the following hypothesis about how CA3 inputs impinging on CA1 PCs during hippocampal oscillations undergo LTP in a healthy brain [16-19]: gamma-frequency spikes of CA1 PCs during thetanested gamma oscillations generated by perisomatictargeting PV interneurons recruits SST interneurons, which in turn disinhibits CA1 PCs' perisomatic dendrites, creating a window of opportunity for tLTP induction. To test this hypothesis, we built a computational network model consisting of CA1 PC, PV, and SST interneurons, together with CA3 input synapsing onto proximal dendritic spines of the CA1 PC providing feedforward inhibition to CA1 PC by activating an inhibitory interneuron (IN) (Fig. 7a). A PV interneuron was reciprocally connected to the CA1 PC while a SST interneuron disinhibited the IN. Parameters were tuned to reflect the in vitro-recorded firing rate-input current relationship (Fig. 7b, Additional file 4: Figure S4c, l). The excitatory CA3-CA1 synapse was modeled to undergo a deterministic intracellular $\mathrm{Ca}^{2+}$ concentration $\left(\left[\mathrm{Ca}^{2+}\right]_{\mathrm{i}}\right)^{2}$ dependent tLTP induction (Fig. 7c). In this model, sinusoidal $5-\mathrm{Hz}$ current input that mimics blue light stimulation delivered to ChR2-expressing CA1 PC (Fig. 7d) activated the reciprocally connected PV interneuron to entrain CA1 PC and SST interneuron spikes at gamma oscillations, as shown in the spike raster plot (Fig. 7e). Such gamma-frequency-entrained SST interneuron's spikes inhibited the IN from spiking (Fig. 7e, IN), and when CA3 input was activated at the rising phase of theta oscillations, SST interneuron-mediated disinhibition allowed the $\left[\mathrm{Ca}^{2+}\right]_{i}$ of CA1 PC spike to cross the threshold for tLTP induction (Fig. 7g, h). In contrast, in a network model without SST interneuron (Fig. 7f), CA3 input-activated feedforward inhibition (Fig. 7f, IN) blocked tLTP induction (Fig. 7g, h). Modulation of SST interneuron activation had no effect on the entrainment of PV interneurons at gamma-frequency and phaselocking of their spikes relative to CA1 PC-generated gamma-frequency spikes (Additional file 12: Figure S12). These results further underscore the differential roles of PV and SST interneurons in hippocampal theta-nested gamma oscillations and tLTP induction, respectively, and suggest how the optogenetic activation of PV and SST could have restored gamma oscillations and tLTP in $\mathrm{A} \beta \mathrm{O}_{1-42}$-treated slices.

\section{Discussion}

Here we have provided the first experimental evidence on how $\mathrm{A} \beta \mathrm{O}_{1-42}$ causes synapse-specific dysfunction in 


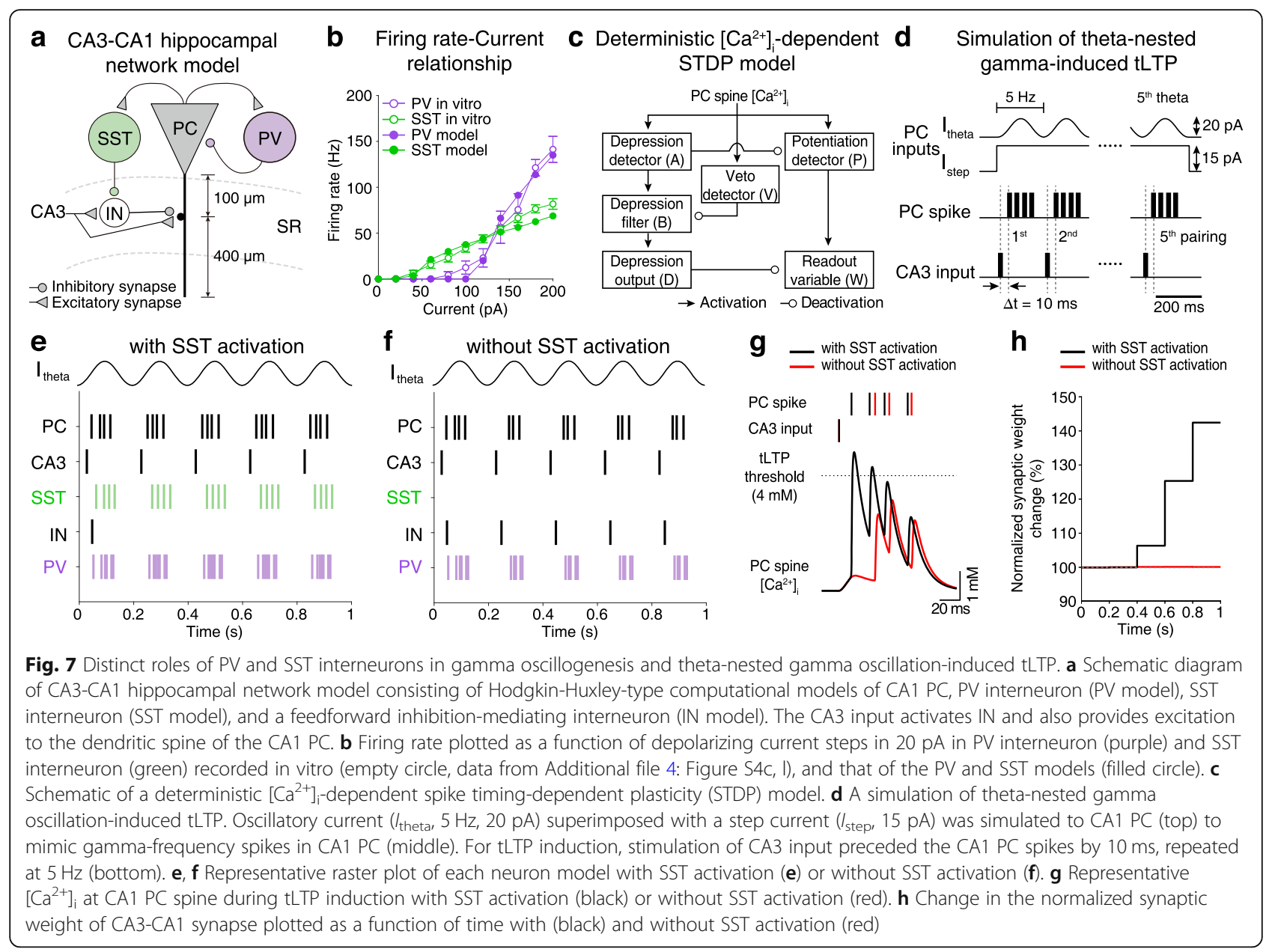

hippocampal inhibitory circuits to impair theta-nested gamma oscillations and theta-nested gamma oscillationinduced tLTP. $A \mathrm{OO}_{1-42}$ selectively disrupted reciprocal PC-to-PV and PV-to-PC synapses, which decreased the peak power of theta-nested gamma oscillations and desynchronized the phase of spikes and synaptic currents relative to gamma cycles (Fig. 1, 2, 3, 4). In contrast, $\mathrm{A} \beta \mathrm{O}_{1-42}$ had no effect on either PC-to-SST synapse or SST-to-PC synapses, but it did selectively disrupt SST interneuronmediated disinhibition to block NMDAR-mediated tLTP at CA3-to-CA1 synapses induced by theta-nested gamma oscillation-like stimulation (Figs. 5 and 6). Importantly, optical stimulation of PV and SST interneurons selectively restored theta-nested gamma oscillations and oscillationinduced tLTP, respectively, which strongly supports the conclusion that these phenomena were the result of synapse-specific dysfunctions of PV and SST interneurons induced by $\mathrm{A} \beta \mathrm{O}_{1-42}$.

Based on our in vitro experimental observations, we built a computational network model of CA1 PC, PV, and SST interneurons which allowed us to infer possible reasons for why hippocampal oscillations are conducive to
LTP in a healthy brain [16-19]. From our simulation results, we were able to see how perisomatic-targeting PV interneurons entrain both CA1 PC and SST interneurons at gamma-frequency which allowed for the SST interneuron to disinhibit CA3 input-activated feedforward inhibition onto CA1 PCs' proximal dendrites, creating a time window for tLTP induction (Fig. 7). Thus, PV and SST interneurons have distinct functional roles in the induction of synaptic plasticity in different compartments of the CA1 PC, and the accumulation of $\mathrm{A} \mathrm{O}_{1-42}$ seen in Alzheimer's disease may cause memory deficits due to impairment of these synaptic plasticity mechanisms.

Although all of our experiments are conducted in vitro, the gamma oscillation impairment observed in our study shares many similarities with the effects of $A \beta$ on kainate-induced gamma oscillations in vitro [9] as well as gamma oscillations recorded in vivo in mouse models of Alzheimer's disease [5-8]. Also, our finding that optical stimulation of PV interneurons can restore gamma oscillations is consistent with previous results showing that manipulations of PV interneurons $[5,8]$ or PV-like fast-spiking interneurons were able to restore 
gamma oscillations in Alzheimer's disease mouse models in vivo [7]. However, unlike previous studies using animal models with the late phase of Alzheimer's disease $[5,7,8]$, the acute effects of $\mathrm{A} \beta \mathrm{O}_{1-42}$ that we uncovered here may only account for the early phase of Alzheimer's disease. In Alzheimer's disease mouse models such as APP/PS1 mice [40] and hAPPJ20 mice [5], spike firing rates and membrane potentials of PV interneuron are increased while in early phase of Alzheimer's disease, pathological effects of $\mathrm{A} \mathrm{O}_{1-42}$ are mainly limited to synaptic dysfunctions with the intrinsic neuronal properties are spared [41], which is consistent with our results (Figs. 2 and 3 and Additional file 4: Figure S4). Thus, optogenetic activation of PV interneurons could have restored theta-nested gamma oscillations by directly depolarizing PV interneurons, which in turn compensate for the $\mathrm{A} \beta \mathrm{O}_{1-42}$-induced reduced $\mathrm{PV}$ interneuron-evoked EPSCs to CA1 PC (Fig. 2) to resynchronize CA1 PC spikes during theta-nested gamma oscillations (Fig. 4), consequently leading to the restoration of theta-nested gamma oscillations. In addition to the reduction in gamma oscillation power, epileptic hyper-synchronous activities are widely observed in human patients with Alzheimer's disease $[6,42]$ and in genetically modified Alzheimer's disease mouse models $[5,6,27,43,44]$. Since the occurrence of epileptic activities in Alzheimer's disease mouse models requires the abnormal aggregation of $A \beta$ fibrils [43] and tau protein [44], but not $\mathrm{A} \beta \mathrm{O}_{1-42}$ [43], it may be that hyper-synchrony may develop with Alzheimer's disease progression $[6,45]$. In fact, it is well established that $\mathrm{A} \mathrm{OO}_{1-42}$ causes hyperexcitability in excitatory neurons [26]. Also, the increase in EPSC and decrease in IPSC amplitudes in CA1 PC during kainate-induced gamma oscillations under $\mathrm{A} \beta \mathrm{O}_{1-42}$ pathology was observed in vitro [9]. Thus, it may be that the balance between excitation and inhibition is disrupted in Alzheimer's disease but how the same neural circuit alternates between hypo- and hyper-synchrony requires further investigation.

Although many studies manipulated PV interneurons in Alzheimer's disease studies [5, 7, 8], our study is the first to directly show how manipulation of SST interneurons could alleviate Alzheimer's disease-related dysfunctions. In contrast to many studies targeting dysfunctional excitatory synapses [46-49] or LTP induction-related intracellular cascades in order to restore LTP in Alzheimer's disease mouse models [49-51], we show that reinstating SST interneuron-mediated disinhibition [39] is sufficient for restoring tLTP in $\mathrm{A} \mathrm{O}_{1-}$ 42 -treated slices in vitro (Figs. 5 and 6). In fact, SST interneuron-mediated disinhibition unmasks the backpropagating spike required for the induction of tLTP $[52,53]$. Thus, our results suggest that SST interneurons' neural circuit dysfunction could explain the tLTP impairment caused by acute application of $\mathrm{A} \beta \mathrm{O}_{1-42}$ resembling early stages of Alzheimer's disease, further supported by our in silico hippocampal network simulation (Fig. 7, Additional file 12: Figure S12). Although we did not get to identify the interneuron subtype that provides disinhibition to CA1 PC through SST interneuron activation, CCK-positive interneurons such as Schaffer collateral-associated cells [54-56] or bistratified cells [39] that are located in the stratum radiatum could be potential candidates. Thus, identifying the interneuron subtypes involved in disinhibition could help target the disinhibitory synapse that is impaired by $\mathrm{A} \mathrm{O}_{1-42}$ pathology. A recent study reported that optogenetic activation of OLM interneurons can induce type 2 theta oscillations in vivo [31], indicating that SST interneurons may also contribute to the generation of theta oscillations in addition to providing disinhibition to CA1 PC in vivo. Since we optically stimulated theta oscillations in order to induce gamma oscillations in vitro, our data cannot resolve the individual contribution of PV or SST interneurons on theta oscillation impairment in Alzheimer's disease [57, 58]. Moreover, it is possible that theta-nested gamma oscillations could play a role in the induction of synaptic plasticity in interneurons [59]; thus, the neural circuit mechanism linking theta-nested gamma oscillations and tLTP may be more intricate than suggested in the present study (Fig. 7). Interestingly, a recent study reported re-emergence of LTP in aged Tg2576 Alzheimer's disease mice which correlates with a decrease in PV interneuron number [60]. Thus, the specific manner in which PV and SST interneurons are affected as the pathologies of Alzheimer's disease progress with age in vivo to disrupt synaptic plasticity requires further investigation. Nonetheless, our data suggests that targeted manipulation of interneuron populations in the hippocampus may be a promising approach for treatments of early-stage Alzheimer's disease.

Although the optogenetic manipulation technique we adopted in this study targeted CA1 PV and SST interneurons, in CA1 alone, there are more than 20 interneuron subtypes $[61,62]$ and PV and SST interneurons do not relate to specific interneuron types, nor indeed are these two markers entirely non-overlapping in CA1 [63-68]. PV can be expressed in both axo-axonic and fast-spiking interneurons, and SST can be found not only in oriens lacunosum-moleculare interneurons, but in various long-range projecting interneurons, too. Indeed, bistratified cells (found in stratum oriens) express both PV and SST [54, 69-71]. Therefore, care is warranted in interpreting our results.

\section{Conclusions}

In summary, by optogenetically manipulating PV and SST interneurons, here we showed for the first time that $\mathrm{A} \beta \mathrm{O}_{1-42}$ causes synapse-specific dysfunctions in PV and 
SST interneurons' synapses, which allows us to uncover how $\mathrm{A} \mathrm{O}_{1-42}$ causes concomitant impairments of hippocampal theta-nested gamma oscillations and oscillationinduced tLTP at CA3-to-CA1 synapses. Thus, our findings provide crucial insight that will help guide future studies aimed at identifying the molecular target that gives rise to $\mathrm{A} \beta \mathrm{O}_{1-42}$-induced synapse-specific dysfunctions, potentially leading to novel therapeutic targets for Alzheimer's disease.

\section{Methods}

\section{Animals}

Three different lines of mice, C57BL/6 mice, PV-Cre knock-in mice (C57BL/6 background, Jackson Laboratory, stock \#017320), and SST-IRES-Cre (C57BL/6 background, Jackson Laboratory, stock \#013044) knock-in mice (4-11 weeks old) were used [72]. All animals were kept in 12:12-h light-dark cycles with food and water available ad libitum. All animal care and experimental procedures were approved by the Institutional Animal Care and Use Committee of Korea University (KUIACUC-2017-112).

\section{Virus}

AAV particles were purchased from the UNC Vector Core. To express ChR2 [73] selectively in CA1 PC, AAV5-CaMKII-hChR2(E123T/T159C)-p2A-mCherryWPRE $\left(3.8 \times 10^{12}\right.$ virus molecules $\left./ \mathrm{ml}, 1 \mu \mathrm{l}\right)$ was injected in all three different lines of mice bilaterally into the hippocampus. For the selective expression of eYFP, Arch, ChR2, or C1V1 on PV or SST interneurons, AAV2-EF1a-DIO-EYFP $\left(4.6 \times 10^{12}\right.$ virus molecules $/ \mathrm{ml}$, $1 \mu \mathrm{l})$, AAV5-EF1a-DIO-eArch3.0-EYFP $\left(5 \times 10^{12}\right.$ virus molecules/ml, $1 \mu \mathrm{l}$ ), AAV5-EF1a-DIO-hChR2(E123T/ T159C)-p2A-mCherry-WPRE $\left(3.8 \times 10^{12}\right.$ virus molecules/ml, $1 \mu \mathrm{l}$ ), or AAV2-EF1a-DIO-C1V1(E162T)-TSp2A-EYFP-WPRE $\left(3 \times 10^{12}\right.$ virus molecules/ml, $\left.1 \mu \mathrm{l}\right)$ were injected bilaterally into the hippocampus of in PVCre or SST-Cre mice.

\section{Stereotaxic virus injections}

Mice were deeply anesthetized under $2 \%$ isoflurane (2 $\mathrm{ml} / \mathrm{min}$ flow rate) and head-fixed into a stereotaxic frame (Stoelting Co.). Craniotomies were made bilaterally to target CA1 area of the hippocampus for viral injections (from bregma: anteroposterior $-2.70 \mathrm{~mm}$, lateral $\pm 2.50 \mathrm{~mm}$, and dorsoventral $-1.75 \mathrm{~mm}$ or anteroposterior $-2.56 \mathrm{~mm}$, lateral $\pm 2.6 \mathrm{~mm}$, and dorsoventral $-1.85 \mathrm{~mm}$ ). One microliter of each virus suspension was injected into the CA1 area of the hippocampus at a rate of $0.15 \mu \mathrm{l} / \mathrm{min}$ through a Hamilton syringe using a motorized stereotaxic injector (Stoetling Co.). The syringe was left in the brain for more than $5 \mathrm{~min}$ to allow for virus diffusion. The scalp was sutured and disinfected with antibiotic, after which the mice were returned to their home cage for recovery for at least 14 days.

\section{Preparation and treatment of $A \mathrm{BO}_{1-42}$ to hippocampal slices}

Soluble $A \mathrm{OO}_{1-42}$ was prepared following methods in Lambert et al. [4] with a slight modification [74]. $A \beta_{1-42}$ or $\mathrm{A} \beta_{42-1}$ powder (Bachem) was dissolved in 1,1,1,3,3,3hexafluoro-2-propanol (HFIP, Sigma Aldrich) for monomerization at a final concentration of $1 \mathrm{mM}$ and incubated for $90 \mathrm{~min}$. HFIP was evaporated under vacuum condition (SpeedVac). The remaining thin and clear film of $A \beta_{1-42}$ or $A \beta_{42-1}$ was dissolved in dimethyl sulfoxide (DMSO, Sigma Aldrich) to make $5 \mathrm{mM} \mathrm{A} \beta_{1-42}$ or $\mathrm{A} \beta_{42-}$ 1 stock, which was aliquoted and frozen at $-20^{\circ} \mathrm{C}$. The $A \beta_{1-42}$ or $A \beta_{42-1}$ stock was thawed and diluted to $100 \mu \mathrm{M}$ in artificial cerebrospinal fluid (aCSF, containing (in $\mathrm{mM}$ ): $126 \mathrm{NaCl}, 3 \mathrm{KCl}, 1.25 \mathrm{NaH}_{2} \mathrm{PO}_{4}, 2 \mathrm{MgSO}_{4}, 2$ $\mathrm{CaCl}_{2}, 25 \mathrm{NaHCO}_{3}$, and 10 glucose at pH 7.2-7.4 bubbled with $95 \% \mathrm{O}_{2} / 5 \% \mathrm{CO}_{2}$ ). After dilution, $\mathrm{A} \beta_{1-42}$ or $\mathrm{A} \beta_{42-1}$ solution was incubated for $18 \mathrm{~h}$ at $4{ }^{\circ} \mathrm{C}$ for $\mathrm{A} \beta$ oligomerization. Before the recording, $2 \%$ DMSO (vehicle) and $100 \mu \mathrm{M} A \beta \mathrm{O}_{1-42}$ or $\mathrm{A}_{3 \mathrm{O}_{42-1}}$ were treated into hippocampal slices in $31.2 \mathrm{ml}$ of aCSF for $20 \mathrm{~min}$ by diluting it to a final concentration of $200 \mathrm{nM} \mathrm{A} \beta \mathrm{O}_{1-42}$ or $\mathrm{A} \beta \mathrm{O}_{42-1}$ in $0.004 \%$ DMSO for each condition.

\section{Western blot analysis Sodium dodecyl sulfate-polyacrylamide gel electrophoresis (SDS-PAGE)}

$\mathrm{A} \beta \mathrm{O}_{1-42}$ were prepared as described above and resolved on a nonreducing 4-15\% tris-glycine-SDS-PAGE gels with LDS sample buffers [75]. The gel was transferred on to a $0.2-\mu \mathrm{m}$ PVDF membrane (Bio-Rad) according to the manufacturer's recommendation. Membranes were blocked in 5\% bovine serum albumin (BSA) in trisbuffered saline containing $0.01 \%$ Tween 20 for $1 \mathrm{~h}$ at room temperature. Blots were incubated in the primary antibody mOC64 (rabbit monoclonal against amino acid residues 3-6 of A $\beta$; Cat\# ab201060, Lot\# GR3235744-4, RRID: AB_2818982, Abcam) [76] at 1:200 dilution overnight at $4{ }^{\circ} \mathrm{C}$. Immunoreactivity was detected with enhanced chemiluminescence (Bio-Rad) and imaged using Fluorchem E system (ProteinSimple). Molecular weight values were estimated using Precision Plus Protein ${ }^{\text {Tx }}$ Dual Color Standards (Bio-rad).

\section{Native PAGE}

$\mathrm{A} \beta \mathrm{O}$ sample was diluted with native PAGE sample buffer (Bio-rad) and then subjected to native PAGE using a 4-15\% tris-glycine gel with the tris-glycine running buffer (Bio-rad). Following transfer to PVDF membrane, membranes were blocked in 5\% BSA in Tris-buffered saline containing $0.01 \%$ Tween 20 for $1 \mathrm{~h}$ at room 
temperature. Blots were probed using rabbit monoclonal A $\beta$ antibody (mOC64, 1:200, Cat\# ab201060, Lot\# GR3235744-4, RRID: AB_2818982, Abcam) overnight at $4{ }^{\circ} \mathrm{C}$. Immunoreactivity and imaging were performed as described above.

\section{In vitro hippocampal slice preparation}

Mice were deeply anesthetized using $1.25 \%$ Avertin solution $(8 \mathrm{~g}$ of 2, 2, 2-Tribromoethanol and $5.1 \mathrm{ml}$ of 2methyl-2-butanol in $402.9 \mathrm{ml}$ saline, Sigma Aldrich) at a delivery rate of $0.2 \mathrm{ml} / 10 \mathrm{~g}$ body weight and perfused with ice-cold cutting solution (containing (in $\mathrm{mM}$ ): 180 sucrose, $2.5 \mathrm{KCl}, 1.25 \mathrm{NaH}_{2} \mathrm{PO}_{4}, 25 \mathrm{NaHCO}_{3}, 11$ glucose, $2 \mathrm{MgSO}_{4}$, and $1 \mathrm{CaCl}_{2}$ at $\mathrm{pH} 7.2-7.4$ oxygenated with $\left.95 \% \mathrm{O}_{2} / 5 \% \mathrm{CO}_{2}\right)$. Either coronal or horizontal hippocampal slices $(300-400 \mu \mathrm{m})$ were cut using a vibratome (VT $1000 \mathrm{~S}$, Leica Microsystems). Slices were allowed to recover for $20 \mathrm{~min}$ in a mixture of cutting solution and aCSF solution at 1:1 ratio, after which the slices were further incubated in aCSF for at least $1 \mathrm{~h}$ at $30-32^{\circ} \mathrm{C}$ before performing electrophysiological recordings. To compare between DMSO and $\mathrm{A} \mathrm{O}_{1-42}$ conditions in the same slice (Fig. 1, Fig. 4c-i), hippocampal slice was first treated with $2 \%$ DMSO in aCSF for 20 min and then the same hippocampal slice was treated with $100 \mu \mathrm{MA} \mathrm{O}_{1-42}$ or $\mathrm{A} \beta \mathrm{O}_{42-1}$ in aCSF by diluting to a final concentration of $200 \mathrm{nM}$ for $20 \mathrm{~min}$. In all other experiments (Figs. 2, 3, 5, and 6 and Additional file 3: Figure S3, Additional file 4: Figure S4, and Additional file 11: Figure S11), hippocampal slices were treated with either $2 \%$ DMSO or $100 \mu \mathrm{M} \mathrm{A} \beta \mathrm{O}_{1-42}$ or $\mathrm{A} \beta \mathrm{O}_{42-1}$ in aCSF by diluting to a final concentration of $200 \mathrm{nM}$ for $20 \mathrm{~min}$ before performing electrophysiological recordings.

\section{In vitro field and patch-clamp recordings}

Slices were moved to a recording chamber filled with aCSF $\left(30-32{ }^{\circ} \mathrm{C}\right)$, and CA1 area of the hippocampus was identified under the guidance of differential interference contrast microscopy (BW51W, Olympus). LFP was recorded in the CA1 PC layer using a borosilicate glass electrode (2-4M $\Omega$ ) filled with aCSF (Figs. 1, 2, 3, and 4 and Additional file 2: Figure S2, Additional file 3: Figure S3, Additional file 5: Figure S5, Additional file 6: Figure S6, and Additional file 7: Figure S7). In some experiments (Figs. $2 c-h, 3 a-g$, and $4 j-n$ ), LFP recordings were simultaneously performed with whole-cell patch-clamp recordings from either CA1 PC, PV, or SST interneurons using borosilicate glass electrode $(4-8 \mathrm{M} \Omega$ ) in either voltage-clamp or current-clamp mode. All synaptic currents were recorded in voltage-clamp recordings with electrodes filled with internal solution containing (in $\mathrm{mM}) 115$ Cesium methanesulfonate (CsMSF), $8 \mathrm{NaCl}$, 10 HEPES, 0.3 GTP-NaCl, 4 ATP-Mg, 0.3 EGTA, 5 QX-
314, and 10 BAPTA (pH 7.3-7.4 and 280-290 mOsm/L). IPSC and EPSC were recorded at the holding potential of $+10 \mathrm{mV}$ and $-80 \mathrm{mV}$, respectively. In recording spikes and intrinsic membrane properties in currentclamp recordings, electrodes were filled with intracellular solution containing (in $\mathrm{mM}$ ) $110 \mathrm{~K}$-gluconate, 40 HEPES, $4 \mathrm{NaCl}$, 4 ATP-Mg, and 0.3 GTP- $\mathrm{NaCl}$ (pH 7.27.3 and $270-300 \mathrm{mOsm} / \mathrm{L}$ ). Intrinsic membrane properties such as spike probability, sag, and rebound potential were measured at resting membrane potential of the neuron in response to current steps $(0 \mathrm{pA}$ to $\pm 200 \mathrm{pA}$ for $500 \mathrm{~ms}$ in $20 \mathrm{pA}$ steps). Input resistance $(\mathrm{M} \Omega)$ and membrane time constant $(\tau)$ were analyzed based on the voltage response to 50 -ms-long negative current step (5 pA) by fitting an exponential curve,

$$
\begin{aligned}
& R_{\text {in }}=\frac{\left(V_{0}-V_{\text {steady }}\right)}{I} \\
& V=V_{0}+A e^{\left(-\frac{t}{\tau}\right)}
\end{aligned}
$$

where $V_{0}$ is the initial voltage, $V_{\text {steady }}$ is the steady state voltage of the first exponential curve fit, $A$ is the amplitude constant, and $I$ is the amplitude of the current step. To record EPSCs evoked by PCs in PV or SST interneurons, a stimulation electrode was placed in the alveus on the subiculum side of the CA1 area to stimulate the axons of PC with a radial cut made between CA1 and subiculum to block the activation of CA3 axons (Fig. 2ip). To analyze the S-R curve of PC-evoked EPSCs in PV or SST interneurons, alveus was stimulated using a single electrical stimulation pulse $(100 \mu \mathrm{s})$ at six different intensities (10, 50, 100, 150, 200, and $300 \mu \mathrm{A}$, Fig. 2j, n). The alveus stimulation intensity which gave $50 \%$ of the maximal EPSC response (half-maximal stimulus, 115$210 \mu \mathrm{A}$ ) was used in subsequent experiments measuring PPR and short-term plasticity, for which a train of ten stimulation pulses at $50 \mathrm{~Hz}(100 \mu \mathrm{s} ; 115-210 \mu \mathrm{A})$ were delivered (Fig. 2k, o). Total charge of PC-evoked EPSCs was calculated by integrating the area under the EPSC trains (Fig. 2l, p). All signals were amplified (MultiClamp 700B amplifier, Molecular Devices), low-pass filtered at $10 \mathrm{kHz}$, and acquired at $5 \mathrm{kHz}$ using ITC-18 data acquisition interface (HEKA Elektronik). Igor Pro software (WaveMetrics) was used for generating command signals, acquiring data as well as data analysis. In currentclamp recordings, only cells with resting membrane potential negative to $-50 \mathrm{mV}$ and with input resistance in the range of $100-400 \mathrm{M} \Omega$ were included in the analysis. Reported voltages are corrected for the liquid junction potential, which was calculated as $\sim 10 \mathrm{mV}$. In voltageclamp recordings, $10 \mathrm{~min}$ was allowed after breakthrough for stabilization before recordings commenced. Series and input resistance were monitored throughout 
the experiment, and cells with $>20 \%$ change in series resistance were discarded.

\section{Light-induced theta-nested gamma oscillations and gamma phase analysis}

For the induction of theta-nested gamma oscillations, ChR2-expressing PCs were activated by sinusoidal $(5 \mathrm{~Hz})$ blue light $(470 \mathrm{~nm})$ [34] (Fig. 1, 2, 3, and 4 and Additional file 2: Figure S2, Additional file 3: Figure S3, Additional file 5: Figure S5, Additional file 6: Figure S6, and Additional file 7: Figure S7). Blue light was delivered using a digital micromirror device (DMD, Polygon400, Mightex) through the objective $(\times 40)$ of the microscope (BX51W, Olympus), which covered the 550- $\mu \mathrm{m}$ diameter circle of the CA1 area with the center of the illumination positioned at the field electrode. The intensity of the blue light varied between 0 to a maximum intensity of $15 \mathrm{~mW}$, which was controlled using a custommade Arduino-based controller. Igor Pro was used to control DMD and synchronize optical stimulation with the electrophysiological recordings. LFP data were first down-sampled to $1 \mathrm{kHz}$ and band-pass filtered between 20 and $120 \mathrm{~Hz}$ for gamma oscillations. Welch's power spectral densities (PSD) of gamma oscillations (3 repetitions of 1-s theta-nested gamma oscillations) were analyzed to quantify the peak power and peak frequency (Figs. $1 \mathrm{~h}-\mathrm{j}$ and $4 \mathrm{e}-\mathrm{g}$ and Additional file 2: Figure S2, Additional file 3: Figure S3, Additional file 5: Figure S5, Additional file 6: Figure S6, and Additional file 7: Figure S7). Spectrogram of gamma oscillations was generated using short-time Fourier transform with window size = $100 \mathrm{~ms}$ and step size $=1 \mathrm{~ms}$. Phase histogram (Fig. $4 \mathrm{k}$ ) of spike or PSC was generated by calculating the instantaneous phase of spikes or PSCs using the Hilbert transform of simultaneously recorded gamma oscillations. The zero phase of gamma oscillations was defined as the peak of the gamma cycle. Probability of spike or PSCs as a function of the phase of reference gamma oscillations was obtained using 20 bins. Resultant vectors were calculated from the phase histogram and plotted in the polar plot (Fig. 4l) from which vector length (Fig. 4m) and vector phase (Fig. $4 n$ ) were calculated. Mean value and statistical significance of vector phase were calculated using the Circular Statistics Toolbox in MATLAB (R2018a) [77]. To generate phase-amplitude comodulograms of theta-nested gamma oscillations (Figs. $1 \mathrm{k}$ and $4 \mathrm{~h}$ and Additional file 3: Figure S3, Additional file 5: Figure S5, and Additional file 6: Figure S6), theta phase was calculated using Hilbert transformation and binned into 20 phase bins with $18^{\circ}$ intervals. At each theta bin, the power spectrogram of gamma oscillations was calculated using short-time Fourier transform. The zero phase of theta oscillations was defined as the peak of the theta cycle. To analyze the phase-amplitude coupling strength of theta- nested gamma oscillations (Figs. 11, 4i, Additional file 3: Figure S3, Additional file 5: Figure S5 and Additional file 6: Figure S6), we calculated the modulation index which is defined as the normalized Kullback-Leibler distance between probability distribution of gamma amplitude per each theta phase bin (18 bins with $20^{\circ}$ intervals) and uniform distribution [78]. To obtain the probability distribution of gamma amplitude, mean amplitude of gamma oscillations for each bin was normalized by the sum of gamma amplitude of total bins. Modulation index value of 0 indicates the absence of phase-amplitude coupling, and the higher modulation index value indicates the stronger phase-amplitude coupling.

\section{Optical modulation of opsin-expressing PV and SST interneurons during patch-clamp recordings}

We expressed Arch or C1V1 in PV and SST interneurons and $\mathrm{ChR} 2$ in $\mathrm{PC}$ in the same hippocampal slice to optically inactivate (Fig. 3b-e, Additional file 5: Figure S5, and Additional file 6: Figure S6) or activate (Fig. 4ad) interneurons during theta-nested gamma oscillations, respectively. The optimal wavelength for stimulating Arch is a green-colored 565-nm light. However, since 565-nm green light also induced excitatory synaptic currents by activating ChR2-expressing PCs (Additional file 7: Figure S7b, d) as well as inducing gamma oscillations in the LFP (Additional file 7: Figure S7b, e) while 590-nm yellow light had no direct effect on ChR2expressing PC (Additional file 7: Figure S7c, d), we used 590-nm yellow light in activating both Arch- and C1V1expressing interneurons during blue light-induced thetanested gamma oscillations. The effectiveness of 590-nm yellow light on Arch-expressing PV and SST interneurons was tested by performing whole-cell voltage-clamp recordings in PV-Cre or SST-Cre mice, respectively (Additional file 8: Figure S8). For the inactivation of Arch-expressing interneurons during theta-nested gamma oscillations (Fig. 3d, e, Additional file 5: Figure S6, and Additional file 6: Figure S6), a tonic yellow light of a fixed light intensity $(1 \mathrm{~s}, 3 \mathrm{~mW})$ was delivered using the DMD. For the activation of C1V1-expressing PV interneuron during theta-nested gamma oscillations (Fig. 4c, d), a sinusoidal (5 Hz) yellow light $(590 \mathrm{~nm})$ was delivered through DMD with the intensity of light sinusoidally varied between 0 and $3 \mathrm{~mW}$ using a custommade Arduino-based controller. To record IPSC evoked by PV and SST interneurons in CA1 PC, ChR2expressing PV and SST interneurons were optically stimulated with blue light $(470 \mathrm{~nm})$ in PV-Cre and SST-Cre mice, respectively, during whole-cell voltage-clamp recordings with the membrane held at $+10 \mathrm{mV}$ (Fig. 3i, $\mathrm{n})$. To analyze the S-R curve of PV/SST interneuronevoked IPSCs in CA1 PC, a single light pulse $(470 \mathrm{~nm}, 5$ $\mathrm{ms}$ ) was delivered to ChR2-expressing $\mathrm{PV}$ or SST 
interneurons at different light powers $(5,10,25,50,75$, $100 \%$ of maximal light power $(15 \mathrm{~mW})$, Fig. 3 j, o). The light power which gave $50 \%$ of the maximal IPSC response (half-maximal stimulus, $3.75-9 \mathrm{~mW}$ ) was used for the subsequent PPR and short-term plasticity analysis, for which a train of ten blue light pulses at $50 \mathrm{~Hz}$ were delivered (470-nm light, 5-ms duration, Fig. 3k, p; 3.75-9 mW). The total charge of PV/SST-evoked IPSCs was calculated by integrating the area under the IPSC train (Fig. 3l, q).

\section{Theta-nested gamma oscillation-induced tLTP induction protocol}

In order to induce theta-nested gamma oscillationinduced tLTP at CA3-CA1 synapse during theta-nested gamma oscillation-like activity, we paired the presynaptic EPSP evoked by SC stimulation with postsynaptic bursts (4 spikes at $100 \mathrm{~Hz}$, each spike elicited with $3 \mathrm{~ms}$ current steps, $800 \mathrm{pA}$ ) with a 10 -ms time window repeated at $5 \mathrm{~Hz}$ [38] for 200 times. EPSPs were evoked every $6 \mathrm{~s}$ using two stimulating electrodes placed in the stratum radiatum of the $\mathrm{CA} 1$ area to activate $\mathrm{SC}$, one for monitoring EPSPs in the control pathway and one for test pathway (Fig. 5a, b). Test and control pathways were stimulated $2 \mathrm{~s}$ apart. EPSP amplitudes were in the range of 3-5 mV (150-400 $\mu \mathrm{A}, 20-80 \mu \mathrm{s}$, Digitimer Ltd.) and were recorded at membrane voltage held at -75 $\mathrm{mV}$. Following $10 \mathrm{~min}$ of baseline EPSP recordings of both pathways, tLTP induction protocol was delivered to the test pathway, after which EPSPs were evoked every $6 \mathrm{~s}$ in both pathways in either DMSO-treated or $\mathrm{A} \beta \mathrm{O}_{1-}$ 42 -treated hippocampal slices prepared from C57BL/6 mice (Fig. $5 \mathrm{c}-\mathrm{e}$ ). To investigate the effect of activation of PV and SST interneurons on tLTP in $\mathrm{A} \mathrm{O}_{1-42}$-treated hippocampal slices, we expressed ChR2 in either PV or SST interneurons and optically stimulated ChR2expressing PV or SST interneurons using tonic blue light (470 nm, X-cite 110LED, Excelitas Tech., 100\% light intensity) during the tLTP induction in $\mathrm{A} \beta \mathrm{O}_{1-42}$-treated hippocampal slices prepared from PV-Cre or SST-Cre mice, respectively (Fig. 5g-j). tLTP induction was repeated in the presence of $50 \mu \mathrm{M}$ D-AP5 to see if the tLTP is NMDA receptor-dependent (Fig. 5d, i). The slope of EPSP was calculated as an index of synaptic efficacy, measured by performing a linear fit on the rising slope of the EPSP between time points corresponding to 20 and $80 \%$ of the EPSP peak amplitude. Changes in synaptic efficacy were estimated as percentage change relative to the mean EPSP slope during the first $10 \mathrm{~min}$ of baseline recordings. To compare synaptic efficacy between neurons and experimental conditions, the mean of the normalized EPSP slope in the time period between 25 and 30 min after the tLTP induction was calculated (Fig. 5f, k).

\section{SST interneuron-mediated disinhibition}

To measure SST interneuron-mediated disinhibition during tLTP induction, we performed whole-cell voltageclamp recordings in $\mathrm{PC}$ to record SC stimulation-evoked IPSC before and during tLTP induction. tLTP induction was performed by pairing of presynaptic EPSP and postsynaptic PC spikes by stimulating the $\mathrm{SC}$ and evoking postsynaptic spikes by stimulating the CA1 axons in the alveus at $100 \mathrm{~Hz}$ (4 pulses) with 10-ms time window, repeated at $5 \mathrm{~Hz}$ for 20 times (Fig. 6b, Additional file 10: Figure S10). All recordings were performed in the presence of D-AP5 $(50 \mu \mathrm{M})$ to prevent synaptic plasticity during tLTP induction. To test if alveus stimulation can elicit spikes in PV and SST interneurons similar to that during blue light-induced theta-nested gamma oscillations as in Fig. 2c, we performed current-clamp recordings in PV and SST interneurons and stimulated alveus at $100 \mathrm{~Hz}$ (4 stimuli) repeated at $5 \mathrm{~Hz}$ (Additional file 9: Figure S9b, d, top). To ensure that alveus stimulation activated PC axons and is not a result of direct stimulation of other pathways, we repeated the experiments in the presence of D-AP5 $(50 \mu \mathrm{M})$ and CNQX $(20 \mu \mathrm{M})$ to block NMDA and AMPA receptors (Additional file 9: Figure S9b, d, bottom). Since alveus stimulation can activate both PV and SST interneurons to provide direct inhibition to $\mathrm{PC}$, we isolated the SC stimulated IPSC during tLTP induction (Additional file 10: Figure S10b, (4), gray) by subtracting the IPSC evoked by alveus stimulation alone (Additional file 10: Figure S10b, (2) Alveus stim, light brown) from the IPSC evoked by pairing SC stimulation with alveus stimulation (Additional file 10: Figure S10b, (3) SC + alveus stim, brown). In calculating the SST interneuron-mediated disinhibition, we took the difference between the IPSC amplitude evoked by SC stimulation alone (Additional file 10: Figure S10b, (1) SC stim, black) and IPSC amplitude calculated in (4) (Additional file 10: Figure S10b, gray). In order to directly test the effect of the activation of SST interneurons on SC stimulation-evoked IPSC, we optically activated ChR2-expressing SST interneurons simultaneously with SC stimulation in the DMSO-treated and $\mathrm{A} \beta \mathrm{O}_{1-42^{-}}$ treated hippocampal slices prepared from SST-Cre mice (Additional file 11: Figure S11).

\section{Drugs}

CNQX, SR95531 (GABAzine), and D-AP5 were purchased from Tocris. PBS, Urea, and $A \beta_{1-42} / A \beta_{42-1}$ powder were purchased from Gibco, Affymetix, and Bachem, respectively. DMSO and the other regents were all purchased from Sigma. For western blot analysis, rabbit monoclonal antibody mOC64was purchased from Abcam (Cat\# ab201060, Lot\# GR3235744-4, RRID: AB 2818982). Horseradish peroxidase (HRP)-conjugated anti-rabbit antibodies (Cat\# 170-6515, Control\# 64170140, RRID: AB_2617112), Mini-PROTEAN TGX 
4-15\% tris-glycine gels, $4 \mathrm{x}$ Laemmli sample buffer, Native sample buffer, and running buffer were all purchased from Bio-Rad.

\section{Fluorescence imaging}

To confirm the expression of opsins in PC, PV, and SST interneurons, hippocampal slices were post-fixed overnight in $4 \%$ paraformaldehyde at $4{ }^{\circ} \mathrm{C}$ and subsequently washed in PBS. Washed slices were mounted with CUBIC mount solution [79], a tissue clearing technique that removes lipids from the sample to enhance transparency in imaging. Images were acquired using a confocal microscope (LSM-700, ZEISS) under a $\times 10$ and $\times 20$ objective.

\section{CA3-CA1 hippocampal network model}

To test whether SST interneuron-mediated disinhibition is required for the theta-nested gamma oscillationinduced tLTP at CA3-CA1 synapse in a computational model, we modeled CA3-CA1 hippocampal network consisted of a multi-compartment PC, singlecompartment PV interneuron (PV model), SST interneuron (SST model), and a feedforward inhibitionmediating interneuron (IN model) as the HodgkinHuxley neuron model [80] (Fig. 7a). The PC model was composed of a soma, an apical dendrite, and a dendritic spine, containing leakage $\left(\mathrm{g}_{\mathrm{L}}\right), \mathrm{Na}^{+}\left(\mathrm{g}_{\mathrm{Na}}\right)$, delayedrectifier $\mathrm{K}^{+}\left(\mathrm{g}_{\mathrm{KDR}}\right)$, A-type $\mathrm{K}^{+}\left(\mathrm{g}_{\mathrm{A}}\right)$, L-type $\mathrm{Ca}^{2+}\left(\mathrm{g}_{\mathrm{CaL}}\right)$, M-type $\mathrm{K}^{+} \quad\left(\mathrm{g}_{\mathrm{KM}}\right)$, afterhyperpolarization-activated $\left(\mathrm{g}_{\mathrm{AHP}}\right)$, and hyperpolarization-activated $\left(\mathrm{g}_{\mathrm{h}}\right)$ channels. PV, SST, and IN models contain leakage $\left(\mathrm{g}_{\mathrm{L}}\right), \mathrm{Na}^{+}\left(\mathrm{g}_{\mathrm{Na}}\right)$, delayed-rectifier $\mathrm{K}^{+}\left(\mathrm{g}_{\mathrm{KDR}}\right)$, and A-type $\mathrm{K}^{+}\left(\mathrm{g}_{\mathrm{A}}\right)$ channels. Spike activities of PV and SST models were calibrated to replicate the in vitro-measured firing rate-current relationship (Fig. 7b, Additional file 4: Figure S4c, l). All morphological, passive, and active parameters of models are shown in Additional file 13: Table S1. CA3-CA1 synapse was modeled at the PC spine located at $100 \mu \mathrm{m}$ from PC soma. CA3 input evoked an EPSP in PC through AMPA and NMDA receptor models. AMPA receptor was modeled as a single-exponential model, and NMDA receptor was modeled with voltage-dependent magnesium block using the following equations,

$$
\begin{aligned}
I_{\mathrm{AMPA}}= & g_{\mathrm{AMPA}} \times\left(e^{-\frac{t}{\tau}}\right) \times\left(V_{m}-E_{\mathrm{AMPA}}\right) \\
I_{\mathrm{NMDA}}= & g_{\mathrm{NMDA}} \times\left(e^{-\frac{t}{\tau_{\text {rise }}}}-e^{-\frac{t}{\tau_{\text {decay }}}}\right) \times\left(V_{m}-E_{\mathrm{NMDA}}\right) / \\
& \left(1+\left(\frac{[m g]}{n}\right) \times e^{-\tau} \times V_{m}\right.
\end{aligned}
$$

where $V_{m}$ is the membrane potential, $I$ is the synaptic current, $g$ is the maximal conductance (AMPA, $0.3 \mathrm{pS}$; NMDA, $1 \mathrm{nS}$ ), $\tau$ is time constants (AMPA, $7 \mathrm{~ms} ; \tau_{\text {rise }}$ for NMDA, $4 \mathrm{~ms}$; $\tau_{\text {decay }}$ for NMDA. $\left.21 \mathrm{~ms}\right), E$ is the reversal potential $(0 \mathrm{mV})$, and $[\mathrm{mg}]$ is the magnesium concentration $(0.5 \mathrm{mM})$. Maximal conductance of AMPA and NMDA was modeled to fit AMPA/NMDA ratio recorded in vitro [81]. Excitatory and inhibitory synapses between PC, PV, SST, and IN models were modeled using a double-exponential model [82]. All excitatory and inhibitory synapses had $\tau_{\text {rise }}$ of $3 \mathrm{~ms}$ and $\tau_{\text {decay }}$ of 15 $\mathrm{ms}$ and $40 \mathrm{~ms}$, respectively. For tLTP simulation, we used a deterministic $\mathrm{Ca}^{2+}$-dependent STDP model (Fig. 7c) [83]. tLTP was considered to be induced when intracellular $\mathrm{Ca}^{2+}$ concentration $\left(\left[\mathrm{Ca}^{2+}\right]_{\mathrm{i}}\right)$ is greater than $4 \mu \mathrm{M}$ which triggered a potentiation detector $(P)$. Synaptic weight of CA3-CA1 AMPA synapse was determined by the readout variable $(W)$. To simulate theta-nested gamma oscillation-induced spikes in $\mathrm{PC}$, we injected oscillatory current $(5 \mathrm{~Hz}, 20 \mathrm{pA})$ superimposed with a tonic step current (15 pA) onto PC soma. For tLTP induction, we paired CA3 input with $\mathrm{PC}$ spikes with a time window of $10 \mathrm{~ms}(\Delta t$, Fig. $7 \mathrm{~d})$. The pairing was repeated five times, and all parameters of the STDP model are listed in Additional file 14: Table S2. In order to investigate whether the presence of SST interneurons in the network model has any effect on the entrainment of PV interneuronal spikes at gamma-frequency, firing rates of $\mathrm{PC}$ and $\mathrm{PV}$ were calculated for the first and the successive theta cycles (Additional file 12: Figure S12a, b). Also, the spike phases of PV interneurons were calculated relative to the PC spike timing where the interspike interval of PC spikes were considered as a period of gamma-frequency and each spike was considered as the trough of gamma cycle (Additional file 12: Figure S12c, d). All simulations were repeated 10 times with Gaussian white noise that generated membrane voltage fluctuations $(\sigma=50 \mathrm{pA}$, peak-to-peak amplitude of fluctuation $=\sim 5 \mathrm{mV},[84])$. All simulations were performed using the NEURON simulator [85] with a sampling rate of $10 \mathrm{kHz}$. The model is available on GitHub (https:// github.com/kuncl/thetagamma_tLTP).

\section{Data analysis}

All data analysis was conducted using Igor Pro or MATLAB with custom-written scripts. Excel (Microsoft) and SPSS (IBM) software were used for statistical analyses.

\section{Statistical analysis}

Data are represented as mean with individual data values or mean \pm SEM. Statistical significance was measured using Student's $t$ test or one-way, one-way repeatedmeasures, and two-way ANOVA followed by post hoc Tukey's test. $p$ value less than 0.05 was considered statistically significant. Statistical significance of spike phases was tested using Watson-Williams multi-sample circular test [86]. 


\section{Supplementary information}

Supplementary information accompanies this paper at https://doi.org/10. 1186/s12915-019-0732-7

Additional file 1 : Figure $\mathbf{S 1}$. Western blot of native PAGE showing $\mathrm{ABO}_{1-42}$ after incubation at $4{ }^{\circ} \mathrm{C}$ for $18 \mathrm{~h}$.

Additional file $\mathbf{2}$ : Figure $\mathbf{S 2}$. Stability of optogenetically-induced theta-nested gamma oscillations in hippocampal slices in vitro.

Additional file $\mathbf{3}$ : Figure S3. Impairment of optogenetically-induced theta-nested gamma oscillations in $\mathrm{ABO}_{1-42}$-treated hippocampal slice in vitro.

Additional file 4 : Figure S4. Intrinsic properties of SST and PV interneurons in DMSO- and $\mathrm{ABO}_{1-42}$-treated hippocampal slices in vitro.

Additional file $\mathbf{5}$ : Figure S5. Optogenetic inactivation of Archexpressing PV interneurons reduces the power of gamma oscillations.

Additional file $\mathbf{6}$ : Figure S6. Optogenetic inactivation of Archexpressing SST interneurons has no effect on the power of gamma oscillations.

Additional file $\mathbf{7}$ : Figure S7. Response of ChR2-expressing PC to different wavelengths of sinusoidal light stimuli.

Additional file 8 : Figure S8. Current response of Arch-expressing PV interneuron, Arch-expressing SST interneuron, and C1V1-expressing PV interneuron to $590 \mathrm{~nm}$ light stimulation.

Additional file $\mathbf{9}$ : Figure $\mathbf{5 9}$. Stimulation of CA1 PC axons with a theta-nested gamma oscillation-like pattern entrains PV and SST interneurons at gamma frequency.

Additional file 10 : Figure S10. Experimental protocol for measuring SST interneuron-mediated disinhibition.

Additional file 11 : Figure S11. Optical stimulation of ChR2-expressing SST interneurons restores $A \mathrm{OO}_{1-42}$-induced impairment of SST interneuron-mediated disinhibition.

Additional file 12 : Figure S12. The effect of SST interneuron activation on spike firing rates and spike phases of CA1 PC and PV interneurons during theta-nested gamma oscillations in silico.

Additional file 13 : Table S1. Parameters of CA1 PC, PV, SST and IN models.

Additional file 14 : Table S2. Parameters of the deterministic $\mathrm{Ca}^{2+}$ dependent STDP model.

\section{Acknowledgements}

We gratefully thank Danny Kanghoon Seo for advices on the optogenetic experimental technique.

\section{Authors' contributions}

KP, JL, and JK designed, conducted, and analyzed all in vitro experiments: BAR and MMK helped setup optogenetic experimental methods; HJJ and JK designed the computational model simulation; HJJ conducted and analyzed computational model simulation data; JK wrote the original draft; and KP, JL, HJJ, MMK, BAR, and JK reviewed and edited the manuscript. All authors read and approved the final manuscript.

\section{Funding}

Human Frontiers Science Program (HFSP) Young Investigator Award (RGY0073/2015) to B.A.R., M.M.K., and J.K., a grant of the Korea Health Technology R\&D Project through the Korea Health Industry Development Institute (KHIDI) funded by the Ministry of Health \& Welfare, Republic of Korea (HI15C3086, HI17C0212, HI19C0646) to J.K., the Brain Convergence Research Program (NRF-2019M3E5D2A01058328) through the National Research Foundation (NRF) funded by the Korean Government (MIST) to J.K., and Global Ph.D Fellowship Program through the National Research Foundation of Korea (NRF) funded by Ministry of Education (NRF2016H1A2A1907615) to K.P.

\section{Availability of data and materials}

All data generated during this study are included in either the manuscript or its additional files.
Ethics approval and consent to participate

Not applicable.

Consent for publication

Not applicable.

\section{Competing interests}

The authors declare that they have no competing interests.

\section{Author details}

'Department of Brain and Cognitive Engineering, Korea University, Seoul 02841, Republic of Korea. ${ }^{2}$ Department of Biological Sciences, University of Toronto Scarborough, Toronto M1C 1A4, Canada. ${ }^{3}$ Department of Physiology, Anatomy and Genetics, University of Oxford, Oxford OX1 3PT, UK

Received: 24 July 2019 Accepted: 16 December 2019

Published online: 15 January 2020

\section{References}

1. Hardy J, Selkoe DJ. The amyloid hypothesis of Alzheimer's disease: progress and problems on the road to therapeutics. Science. 2002:297(5580):353-6.

2. Selkoe DJ. Alzheimer's disease is a synaptic failure. Science. 2002;298(5594): 789-91.

3. Walsh DM, Selkoe DJ. Deciphering the molecular basis of memory failure in Alzheimer's disease. Neuron. 2004:44(1):181-93.

4. Lambert MP, Barlow AK, Chromy BA, Edwards C, Freed R, Liosatos M, Morgan TE, Rozovsky I, Trommer B, Viola KL, et al. Diffusible, nonfibrillar ligands derived from Abeta1-42 are potent central nervous system neurotoxins. Proc Natl Acad Sci U S A. 1998:95(11):6448-53.

5. Verret L, Mann EO, Hang GB, Barth AM, Cobos I, Ho K, Devidze N, Masliah E, Kreitzer AC, Mody I, et al. Inhibitory interneuron deficit links altered network activity and cognitive dysfunction in Alzheimer model. Cell. 2012;149(3): 708-21

6. Palop Jucke L. Network abnormalities and interneuron dysfunction in Alzheimer disease. Nat Rev Neurosci. 2016;17(12):777-92.

7. Martinez-Losa M, Tracy TE, Ma K, Verret L, Clemente-Perez A, Khan AS, Cobos I, Ho K, Gan L, Mucke L, et al. Nav1.1-overexpressing interneuron transplants restore brain rhythms and cognition in a mouse model of Alzheimer's disease. Neuron. 2018;98(1):75-89 e75.

8. laccarino HF, Singer AC, Martorell AJ, Rudenko A, Gao F, Gillingham TZ, Mathys $\mathrm{H}$, Seo J, Kritskiy O, Abdurrob F, et al. Gamma frequency entrainment attenuates amyloid load and modifies microglia. Nature. 2016; 540(7632):230-5

9. Kurudenkandy FR, Zilberter M, Biverstal H, Presto J, Honcharenko D, Stromberg R, Johansson J, Winblad B, Fisahn A. Amyloid-beta-induced action potential desynchronization and degradation of hippocampal gamma oscillations is prevented by interference with peptide conformation change and aggregation. J Neurosci. 2014;34(34):11416-25.

10. Wang J, Ikonen S, Gurevicius K, van Groen T, Tanila H. Alteration of cortical EEG in mice carrying mutated human APP transgene. Brain Res. 2002;943(2): 181-90.

11. Walsh DM, Klyubin I, Fadeeva JV, Cullen WK, Anwyl R, Wolfe MS, Rowan MJ, Selkoe DJ. Naturally secreted oligomers of amyloid beta protein potently inhibit hippocampal long-term potentiation in vivo. Nature. 2002:416(6880): 535-9.

12. Lei M, Xu H, Li Z, Wang Z, O'Malley TT, Zhang D, Walsh DM, Xu P, Selkoe DJ, Li S. Soluble Abeta oligomers impair hippocampal LTP by disrupting glutamatergic/GABAergic balance. Neurobiol Dis. 2016:85:111-21.

13. Buzsaki G, Moser El. Memory, navigation and theta rhythm in the hippocampal-entorhinal system. Nat Neurosci. 2013;16(2):130-8.

14. Csicsvari J, Jamieson B, Wise KD, Buzsaki G. Mechanisms of gamma oscillations in the hippocampus of the behaving rat. Neuron. 2003;37(2): $311-22$

15. Buzsaki G, Leung LW, Vanderwolf $\mathrm{CH}$. Cellular bases of hippocampal EEG in the behaving rat. Brain Res. 1983:287(2):139-71.

16. Buzsaki G. Theta oscillations in the hippocampus. Neuron. 2002;33(3):325-40.

17. Vertes RP. Hippocampal theta rhythm: a tag for short-term memory. Hippocampus. 2005;15(7):923-35.

18. Lisman JE, Idiart MA. Storage of $7+/-2$ short-term memories in oscillatory subcycles. Science. 1995;267(5203):1512-5. 
19. Jensen O, Lisman JE. Theta/gamma networks with slow NMDA channels learn sequences and encode episodic memory: role of NMDA channels in recall. Learn Mem. 1996;3(2-3):264-78.

20. Cobb SR, Buhl EH, Halasy K, Paulsen O, Somogyi P. Synchronization of neuronal activity in hippocampus by individual GABAergic interneurons. Nature. 1995:378(6552):75-8.

21. Fisahn A, Pike FG, Buhl EH, Paulsen O. Cholinergic induction of network oscillations at $40 \mathrm{~Hz}$ in the hippocampus in vitro. Nature. 1998;394(6689): 186-9.

22. Mann EO, Mody I. Control of hippocampal gamma oscillation frequency by tonic inhibition and excitation of interneurons. Nat Neurosci. 2010;13(2): 205-12.

23. Mann EO, Suckling JM, Hajos N, Greenfield SA, Paulsen O. Perisomatic feedback inhibition underlies cholinergically induced fast network oscillations in the rat hippocampus in vitro. Neuron. 2005;45(1):105-17.

24. Gulyas Al, Szabo GG, Ulbert I, Holderith N, Monyer H, Erdelyi F, Szabo G, Freund TF, Hajos N. Parvalbumin-containing fast-spiking basket cells generate the field potential oscillations induced by cholinergic receptor activation in the hippocampus. J Neurosci. 2010;30(45):15134-45.

25. Ferguson KA, Huh CY, Amilhon B, Williams S, Skinner FK. Experimentally constrained CA1 fast-firing parvalbumin-positive interneuron network models exhibit sharp transitions into coherent high frequency rhythms. Front Comput Neurosci. 2013;7:144.

26. Busche MA, Eichhoff $G$, Adelsberger $H$, Abramowski D, Wiederhold KH, Haass C, Staufenbiel M, Konnerth A, Garaschuk O. Clusters of hyperactive neurons near amyloid plaques in a mouse model of Alzheimer's disease. Science. 2008;321(5896):1686-9.

27. Palop JJ, Chin J, Roberson ED, Wang J, Thwin MT, Bien-Ly N, Yoo J, Ho KO, Yu GQ, Kreitzer A, et al. Aberrant excitatory neuronal activity and compensatory remodeling of inhibitory hippocampal circuits in mouse models of Alzheimer's disease. Neuron. 2007:55(5):697-711.

28. Wang Z, Jackson RJ, Hong W, Taylor WM, Corbett GT, Moreno A, Liu W, Li S, Frosch MP, Slutsky I, et al. Human brain-derived Abeta oligomers bind to synapses and disrupt synaptic activity in a manner that requires APP. J Neurosci. 2017;37(49):11947-66.

29. Garcia-Marin V, Blazquez-Llorca L, Rodriguez JR, Boluda S, Muntane G, Ferrer I, Defelipe J. Diminished perisomatic GABAergic terminals on cortical neurons adjacent to amyloid plaques. Front Neuroanat. 2009;3:28.

30. Kullmann DM. Interneuron networks in the hippocampus. Curr Opin Neurobiol. 2011;21(5):709-16.

31. Mikulovic S, Restrepo CE, Siwani S, Bauer P, Pupe S, Tort ABL, Kullander K, Leao RN. Ventral hippocampal OLM cells control type 2 theta oscillations and response to predator odor. Nat Commun. 2018;9(1):3638.

32. Schmid LC, Mittag M, Poll S, Steffen J, Wagner J, Geis HR, Schwarz I, Schmidt B, Schwarz MK, Remy S, et al. Dysfunction of somatostatin-positive interneurons associated with memory deficits in an Alzheimer's disease model. Neuron. 2016:92(1):114-25.

33. Chen L, Saito T, Saido TC, Mody I. Novel quantitative analyses of spontaneous synaptic events in cortical pyramidal cells reveal subtle parvalbumin-expressing interneuron dysfunction in a knock-in mouse model of Alzheimer's disease. eNeuro. 2018;5(4):0059-18.2018.

34. Butler JL, Mendonca PR, Robinson HP, Paulsen O. Intrinsic cornu ammonis area 1 theta-nested gamma oscillations induced by optogenetic theta frequency stimulation. J Neurosci. 2016;36(15):4155-69.

35. Pouille F, Scanziani M. Routing of spike series by dynamic circuits in the hippocampus. Nature. 2004;429(6993):717-23.

36. O'Keefe J, Recce ML. Phase relationship between hippocampal place units and the EEG theta rhythm. Hippocampus. 1993;3(3):317-30.

37. Zheng C, Bieri KW, Hsiao YT, Colgin LL. Spatial sequence coding differs during slow and fast gamma rhythms in the hippocampus. Neuron. 2016; 89(2):398-408

38. Pike FG, Meredith RM, Olding AW, Paulsen O. Rapid report: postsynaptic bursting is essential for 'Hebbian' induction of associative long-term potentiation at excitatory synapses in rat hippocampus. J Physiol. 1999; 518(Pt 2):571-6.

39. Leao RN, Mikulovic S, Leao KE, Munguba H, Gezelius H, Enjin A, Patra K, Eriksson A, Loew $L M$, Tort $A B$, et al. OLM interneurons differentially modulate CA3 and entorhinal inputs to hippocampal CA1 neurons. Nat Neurosci. 2012;15(11):1524-30.

40. Hijazi S, Heistek TS, Scheltens P, Neumann U, Shimshek DR, Mansvelder HD, Smit $A B$, van Kesteren RE. Early restoration of parvalbumin interneuron activity prevents memory loss and network hyperexcitability in a mouse model of Alzheimer's disease. Mol Psychiatry. 2019. https://doi.org/10.1038/ s41380-019-0483-4.

41. Shankar GM, Walsh DM. Alzheimer's disease: synaptic dysfunction and Abeta. Mol Neurodegener. 2009;4:48.

42. Larner AJ. Epileptic seizures in AD patients. NeuroMolecular Med. 2010;12(1): $71-7$.

43. Minkeviciene R, Rheims S, Dobszay MB, Zilberter M, Hartikainen J, Fulop L, Penke B, Zilberter Y, Harkany T, Pitkanen A, et al. Amyloid beta-induced neuronal hyperexcitability triggers progressive epilepsy. J Neurosci. 2009; 29(11):3453-62.

44. Roberson ED, Halabisky B, Yoo JW, Yao J, Chin J, Yan F, Wu T, Hamto P, Devidze N, Yu GQ, et al. Amyloid-beta/Fyn-induced synaptic, network, and cognitive impairments depend on tau levels in multiple mouse models of Alzheimer's disease. J Neurosci. 2011:31(2):700-11.

45. Vossel KA, Tartaglia MC, Nygaard HB, Zeman AZ, Miller BL. Epileptic activity in Alzheimer's disease: causes and clinical relevance. Lancet Neurol. 2017; 16(4):311-22.

46. Kamenetz F, Tomita T, Hsieh H, Seabrook G, Borchelt D, Iwatsubo T, Sisodia S, Malinow R. APP processing and synaptic function. Neuron. 2003;37(6): 925-37.

47. Shankar GM, Bloodgood BL, Townsend M, Walsh DM, Selkoe DJ, Sabatini BL. Natural oligomers of the Alzheimer amyloid-beta protein induce reversible synapse loss by modulating an NMDA-type glutamate receptor-dependent signaling pathway. J Neurosci. 2007;27(11):2866-75.

48. Lacor PN, Buniel MC, Furlow PW, Clemente AS, Velasco PT, Wood M, Viola $\mathrm{KL}$, Klein WL. Abeta oligomer-induced aberrations in synapse composition shape, and density provide a molecular basis for loss of connectivity in Alzheimer's disease. J Neurosci. 2007;27(4):796-807.

49. Hsieh H, Boehm J, Sato C, Iwatsubo T, Tomita T, Sisodia S, Malinow R. AMPAR removal underlies Abeta-induced synaptic depression and dendritic spine loss. Neuron. 2006:52(5):831-43.

50. Snyder EM, Nong Y, Almeida CG, Paul S, Moran T, Choi EY, Nairn AC, Salter MW, Lombroso PJ, Gouras GK, et al. Regulation of NMDA receptor trafficking by amyloid-beta. Nat Neurosci. 2005;8(8):1051-8.

51. Wang Q, Walsh DM, Rowan MJ, Selkoe DJ, Anwyl R. Block of long-term potentiation by naturally secreted and synthetic amyloid beta-peptide in hippocampal slices is mediated via activation of the kinases c-Jun $\mathrm{N}$ terminal kinase, cyclin-dependent kinase 5, and p38 mitogen-activated protein kinase as well as metabotropic glutamate receptor type 5 . J Neurosci. 2004:24(13):3370-8.

52. Magee JC, Johnston D. A synaptically controlled, associative signal for Hebbian plasticity in hippocampal neurons. Science. 1997;275(5297):209-13.

53. Markram H, Lubke J, Frotscher M, Sakmann B. Regulation of synaptic efficacy by coincidence of postsynaptic APs and EPSPs. Science. 1997;275(5297):213-5.

54. Klausberger T. GABAergic interneurons targeting dendrites of pyramidal cells in the CA1 area of the hippocampus. Eur J Neurosci. 2009:30(6):947-57.

55. Basu J, Srinivas KV, Cheung SK, Taniguchi H, Huang ZJ, Siegelbaum SA. A cortico-hippocampal learning rule shapes inhibitory microcircuit activity to enhance hippocampal information flow. Neuron. 2013;79(6):1208-21.

56. Basu J, Zaremba JD, Cheung SK, Hitti FL, Zemelman BV, Losonczy A Siegelbaum SA. Gating of hippocampal activity, plasticity, and memory by entorhinal cortex long-range inhibition. Science. 2016:351(6269):aaa5694.

57. Villette V, Poindessous-Jazat F, Simon A, Lena C, Roullot E, Bellessort B, Epelbaum J, Dutar P, Stephan A. Decreased rhythmic GABAergic septal activity and memory-associated theta oscillations after hippocampal amyloid-beta pathology in the rat. J Neurosci. 2010;30(33):10991-1003.

58. Scott L, Feng J, Kiss T, Needle E, Atchison K, Kawabe TT, Milici AJ, HajosKorcsok E, Riddell D, Hajos M. Age-dependent disruption in hippocampal theta oscillation in amyloid-beta overproducing transgenic mice. Neurobiol Aging. 2012;33(7):1481 e1413-23.

59. Lamsa KP, Heeroma JH, Somogyi P, Rusakov DA, Kullmann DM. AntiHebbian long-term potentiation in the hippocampal feedback inhibitory circuit. Science. 2007:315(5816):1262-6.

60. Huh S, Baek SJ, Lee KH, Whitcomb DJ, Jo J, Choi SM, Kim DH, Park MS, Lee $\mathrm{KH}$, Kim BC. The reemergence of long-term potentiation in aged Alzheimer's disease mouse model. Sci Rep. 2016;6:29152.

61. McBain CJ, Fisahn A. Interneurons unbound. Nat Rev Neurosci. 2001; 2(1):11-23.

62. Klausberger T, Somogyi P. Neuronal diversity and temporal dynamics: the unity of hippocampal circuit operations. Science. 2008;321(5885):53-7. 
63. Jinno S, Kosaka T. Colocalization of parvalbumin and somatostatin-like immunoreactivity in the mouse hippocampus: quantitative analysis with optical dissector. J Comp Neurol. 2000;428(3):377-88.

64. Klausberger T, Magill PJ, Marton LF, Roberts JD, Cobden PM, Buzsaki G, Somogyi P. Brain-state- and cell-type-specific firing of hippocampal interneurons in vivo. Nature. 2003;421(6925):844-8.

65. Somogyi P, Klausberger T. Defined types of cortical interneurone structure space and spike timing in the hippocampus. J Physiol. 2005;562(Pt 1):9-26.

66. Fishell G, Rudy B. Mechanisms of inhibition within the telencephalon: "where the wild things are". Annu Rev Neurosci. 2011;34:535-67.

67. Katona L, Lapray D, Viney TJ, Oulhaj A, Borhegyi Z, Micklem BR, Klausberger T, Somogyi P. Sleep and movement differentiates actions of two types of somatostatin-expressing GABAergic interneuron in rat hippocampus. Neuron. 2014;82(4):872-86.

68. Nassar M, Simonnet J, Lofredi R, Cohen I, Savary E, Yanagawa Y, Miles R, Fricker D. Diversity and overlap of parvalbumin and somatostatin expressing interneurons in mouse presubiculum. Front Neural Circuits. 2015;9:20.

69. Pawelzik H, Hughes DI, Thomson AM. Physiological and morphological diversity of immunocytochemically defined parvalbumin- and cholecystokinin-positive interneurones in CA1 of the adult rat hippocampus. J Comp Neurol. 2002;443(4):346-67.

70. Klausberger T, Marton LF, Baude A, Roberts JD, Magill PJ, Somogyi P. Spike timing of dendrite-targeting bistratified cells during hippocampal network oscillations in vivo. Nat Neurosci. 2004;7(1):41-7.

71. Baude A, Bleasdale C, Dalezios Y, Somogyi P, Klausberger T. Immunoreactivity for the GABAA receptor alpha1 subunit, somatostatin and Connexin36 distinguishes axoaxonic, basket, and bistratified interneurons of the rat hippocampus. Cereb Cortex. 2007;17(9):2094-107.

72. Taniguchi H, He M, Wu P, Kim S, Paik R, Sugino K, Kvitsiani D, Fu Y, Lu J, Lin $Y$, et al. A resource of Cre driver lines for genetic targeting of GABAergic neurons in cerebral cortex. Neuron. 2011;71(6):995-1013.

73. Boyden ES, Zhang F, Bamberg E, Nagel G, Deisseroth K. Millisecondtimescale, genetically targeted optical control of neural activity. Nat Neurosci. 2005;8(9):1263-8.

74. Wang Q, Klyubin I, Wright S, Griswold-Prenner I, Rowan MJ, Anwyl R. Alpha $\checkmark$ integrins mediate beta-amyloid induced inhibition of long-term potentiation. Neurobiol Aging. 2008;29(10):1485-93.

75. Laemmli UK. Cleavage of structural proteins during the assembly of the head of bacteriophage T4. Nature. 1970;227(5259):680-5.

76. Hatami A, Albay R 3rd, Monjazeb S, Milton S, Glabe C. Monoclonal antibodies against Abeta42 fibrils distinguish multiple aggregation state polymorphisms in vitro and in Alzheimer disease brain. J Biol Chem. 2014; 289(46):32131-43.

77. Berens PJJSS: CircStat: a MATLAB toolbox for circular statistics. 2009, 31(10): $1-21$.

78. Tort AB, Komorowski RW, Manns JR, Kopell NJ, Eichenbaum H. Thetagamma coupling increases during the learning of item-context associations. Proc Natl Acad Sci U S A. 2009:106(49):20942-7.

79. Lee E, Choi J, Jo Y, Kim JY, Jang YJ, Lee HM, Kim SY, Lee HJ, Cho K, Jung N, et al. ACT-PRESTO: rapid and consistent tissue clearing and labeling method for 3-dimensional (3D) imaging. Sci Rep. 2016;6:18631.

80. Jang HJ, Kwag J. GABAA receptor-mediated feedforward and feedback inhibition differentially modulate hippocampal spike timing-dependent plasticity. Biochem Biophys Res Commun. 2012;427(3):466-72.

81. Otmakhova NA, Otmakhov N, Lisman JE. Pathway-specific properties of AMPA and NMDA-mediated transmission in CA1 hippocampal pyramidal cells. J Neurosci. 2002;22(4):1199-207.

82. Koch C. Biophysics of computation: information processing in single neurons. New York: Oxford university press; 2004

83. Rubin JE, Gerkin RC, Bi GQ, Chow CC. Calcium time course as a signal for spike-timing-dependent plasticity. J Neurophysiol. 2005:93(5):2600-13.

84. Fernandez FR, White JA. Gain control in CA1 pyramidal cells using changes in somatic conductance. J Neurosci. 2010:30(1):230-41.

85. Hines ML, Carnevale NT. The NEURON simulation environment. Neural Comput. 1997;9(6):1179-209.

86. Zar JH. Statistical procedures for biological-research - a citation classic commentary on biostatistical analysis by Zar..H. CC/Agr Biol Environ. 1989;6:20.

\section{Publisher's Note}

Springer Nature remains neutral with regard to jurisdictional claims in published maps and institutional affiliations.

Ready to submit your research? Choose BMC and benefit from:

- fast, convenient online submission

- thorough peer review by experienced researchers in your field

- rapid publication on acceptance

- support for research data, including large and complex data types

- gold Open Access which fosters wider collaboration and increased citations

- maximum visibility for your research: over $100 \mathrm{M}$ website views per year

At $\mathrm{BMC}$, research is always in progress.

Learn more biomedcentral.com/submissions 